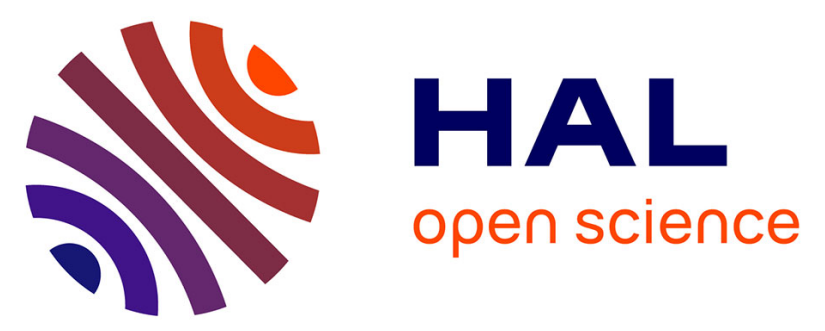

\title{
Sirolimus for treatment of patients with inclusion body myositis: a randomised, double-blind, placebo-controlled, proof-of-concept, phase $2 \mathrm{~b}$ trial
}

Olivier Benveniste, Jean-Yves Hogrel, Lisa Belin, Mélanie Annoussamy, Damien Bachasson, Aude Rigolet, Pascal Laforêt, Gaelle Dzangue-Tchoupou, Joe-Elie Salem, Lee S Nguyen, et al.

\section{To cite this version:}

Olivier Benveniste, Jean-Yves Hogrel, Lisa Belin, Mélanie Annoussamy, Damien Bachasson, et al.. Sirolimus for treatment of patients with inclusion body myositis: a randomised, double-blind, placebocontrolled, proof-of-concept, phase $2 \mathrm{~b}$ trial. The Lancet Rheumatology, 2021, 3 (1), pp.e40-e48. 10.1016/S2665-9913(20)30280-0 . hal-03180889

\section{HAL Id: hal-03180889 \\ https://hal.sorbonne-universite.fr/hal-03180889}

Submitted on 26 Mar 2021

HAL is a multi-disciplinary open access archive for the deposit and dissemination of scientific research documents, whether they are published or not. The documents may come from teaching and research institutions in France or abroad, or from public or private research centers.
L'archive ouverte pluridisciplinaire HAL, est destinée au dépôt et à la diffusion de documents scientifiques de niveau recherche, publiés ou non, émanant des établissements d'enseignement et de recherche français ou étrangers, des laboratoires publics ou privés. 


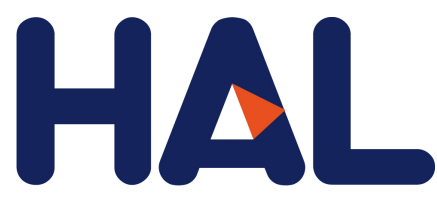

archives-ouvertes

\section{Sirolimus for treatment of patients with inclusion body myositis: a randomised, double-blind, placebo-controlled, proof-of-concept, phase $2 \mathrm{~b}$ trial}

Olivier Benveniste, Jean-Yves Hogrel, Lisa Belin, Mélanie Annoussamy, Damien Bachasson, Aude Rigolet, Pascal Laforêt, Gaelle Dzangue-Tchoupou, Joe-Elie Salem, Lee Nguyen, et al.

\section{To cite this version:}

Olivier Benveniste, Jean-Yves Hogrel, Lisa Belin, Mélanie Annoussamy, Damien Bachasson, et al.. Sirolimus for treatment of patients with inclusion body myositis: a randomised, double-blind, placebocontrolled, proof-of-concept, phase 2b trial. The Lancet Rheumatology, Elsevier, 2021, 3 (1), pp.e40e48. 10.1016/S2665-9913(20)30280-0 . hal-03180889

\section{HAL Id: hal-03180889 \\ https://hal.sorbonne-universite.fr/hal-03180889}

Submitted on 25 Mar 2021

HAL is a multi-disciplinary open access archive for the deposit and dissemination of scientific research documents, whether they are published or not. The documents may come from teaching and research institutions in France or abroad, or from public or private research centers.
L'archive ouverte pluridisciplinaire HAL, est destinée au dépôt et à la diffusion de documents scientifiques de niveau recherche, publiés ou non, émanant des établissements d'enseignement et de recherche français ou étrangers, des laboratoires publics ou privés. 


\section{Sirolimus for treatment of patients with inclusion body myositis: a randomised, double-blind, placebo-controlled, proof-of-concept, phase $2 b$ trial}

Olivier Benveniste, Jean-Yves Hogrel, Lisa Belin, Mélanie Annoussamy, Damien Bachasson, Aude Rigolet, Pascal Laforet, Gaëlle Dzangué-Tchoupou, Joe-Elie Salem, Lee S Nguyen, Tanya Stojkovic, Noel Zahr, Baptiste Hervier, Océane Landon-Cardinal, Anthony Behin, Edith Guilloux, Harmen Reyngoudt, Damien Amelin, Akinori Uruha, Kuberaka Mariampillai, Benjamin Marty, Bruno Eymard, Jean-Sébastien Hulot, Steven A Greenberg, Pierre G Carlier, Yves Allenbach

Sorbonne Université, INSERM U974, Assistance Publique-Hôpitaux de Paris (AP-HP), Department of Internal Medicine and Clinical Immunology Neuromuscular Rare Diseases Reference Center of Paris, Pitié-Salpêtrière University Hospital, Paris, France (Prof O Benveniste MD, A Rigolet MD, G Dzangué-Tchoupou PhD, B Hervier MD, D Amelin, A Uruha MD, K Mariampillai PhD, Y Allenbach MD);

Sorbonne Université, INSERM, Institut Pierre Louis d'Epidémiologie et de Santé Publique, APHP, Hôpitaux Universitaires Pitié Salpêtrière - Charles Foix, Département Biostatistique Santé Publique et Information Médicale, F75013, Paris, France (L Belin PhD);

Neuromuscular Physiology Laboratory, Neuromuscular Investigation Center, Institute of Myology, Pitié-Salpêtrière Hospital, 75651 Paris Cedex 13, France (JY Hogrel PhD, D Bachasson $\mathrm{PhD}$ );

I-Motion Institute, Trousseau Hospital, 26 Avenue du Dr A. Netter, 75012 Paris (M Annoussamy PhD); 
NMR Laboratory, CEA/DRF/IBJF/MIRCen, Neuromuscular Investigation Center, Institute of Myology, Paris, France (H Reyngoudt PhD, B Marty PhD, P G Carlier MD);

Sorbonne Université, INSERM, AP-HP, Hôpitaux Universitaires Pitié Salpêtrière - Charles Foix, Centre d'investigation Clinique Paris-Est, CIC 1421, Department of Pharmacology, F75013, Paris, France (JE Salem MD, L S Nguyen MD, E Guilloux RN, JS Hulot MD);

Clinical Pharmacology \& Center of Clinical Investigation Paris-Est, Sorbonne Université, APHP, INSERM, Paris, France (N Zahr PharmD);

Neuromuscular Reference Center Nord/Est/lle de France, AP-HP, Hôpitaux Universitaires Pitié Salpêtrière - Charles Foix, 75013 Paris, France (Prof P Laforet MD, T Stojkovic MD, A Behin MD, Prof B Eymard MD);

Department of Medicine, University of Montreal, Canada; Division of Rheumatology, Centre Hospitalier de l'Université de Montréal (CHUM), Montreal, Canada; CHUM Research Center (O Landon-Cardinal MD);

Department of Neurology, Brigham and Women's Hospital, Harvard Medical School, Boston, MA, USA (Prof S A Greenberg MD)

Correspondence to Dr. Olivier Benveniste, Department of Internal Medicine and Clinical Immunology, Pitié-Salpêtrière Hospital, 47 Bd de l'Hôpital, 75013 Paris, France olivier.benveniste@aphp.fr 


\section{Summary}

Background Inclusion body myositis (IBM) is the most frequent myositis in people over 50 years old. Conventional immunosuppressive drugs are considered ineffective. When used in organ transplantation, sirolimus can block the proliferation of $\mathrm{T}$ effector cells while preserving T regulatory cells and induce autophagy, all of which are parameters impaired in IBM.

Methods RAPAMI was a prospective, randomised, controlled, double blind, single centre, proof of concept trial. The primary endpoint was relative changes in maximal voluntary quadriceps isometric strength between baseline and 12 months after treatment initiation (M12). Secondary endpoints included changes in strength of other muscle groups (grip, elbow flexion and extension, knee flexion), 6-minute walk distance (6MWD), forced vital capacity (FVC), IBM weakness composite index (IBMWCI), IBM functional rating scale (IBMFRS), health assessment questionnaire without disability index (HAQ-DI), analyses of CD8 $\mathrm{T}$ cell subpopulations by mass cytometry, and the lower limb muscle fat fraction (FF) by quantitative nuclear magnetic resonance imaging.

Findings $A$ total of 44 patients were treated with oral sirolimus $(n=22)$ or placebo $(n=22)$ for 12 months. There was no difference in the primary outcome of relative percentage change from baseline to M12 of the maximal voluntary isometric knee extension strength (median difference $3 \cdot 78,95 \% \mathrm{Cl}[-10 \cdot 61$ to $17 \cdot 31], \mathrm{p}=0.85)$. For secondary outcomes, the differences between the groups were not significant for changes in strength of other muscle groups (grip, elbow flexion and extension, or knee flexion), IBMWCI, IBMFRS, and the lower limb muscle FF but were for HAQ-DI $(-0.27$ [-0.44; -0.01]; $p=0.035)$, the FVC, $(7 \cdot 72[1 \cdot 36 ; 13 \cdot 22] ; p=0 \cdot 006)$, thigh FF (-1.84 [-3.75; -0.40]; $p=0.016)$, and the 6MWD (11.4 [0.36; 20.86]; $p=0.009)$. Ten patients (45\%) had a serious side effect in the sirolimus group, whereas $6(27 \%)$ did in the placebo group. Four (18\%) patients in the sirolimus arm stopped their treatment due to side effects (severe mouth ulcers, aseptic pneumonia, renal insufficiency and peripheral lower limb 
edema), which resolved after withdrawal. Canker sores were the most frequent side effect and were mainly mild or moderate in 10 patients.

Interpretation This study did not provide evidence of the efficacy of sirolimus for treating IBM based on the primary outcome measure and other muscle strength measures and side effects were substantial for some patients. However, we believe there is enough evidence of benefit in certain secondary outcomes to pursue a multicentric phase 3 trial to further assess its safety and efficacy.

Funding Institut national de la santé et de la recherche médicale (Inserm), Direction générale de l'offre de soins (DGOS), and Association Française contre les Myopathies (AFM) 


\section{Introduction}

Inclusion body myositis (IBM) is the most frequent type of myositis in patients over 50 years of age. ${ }^{1}$ Nevertheless, IBM remains a rare disease with an estimated prevalence of 84 per million in people $>65$ years of age. ${ }^{2}$ Its estimated annual cost of care is 35,000 US dollars per year. ${ }^{2}$ The disease is slowly progressive and leads to severe muscle disability, affecting all muscle groups but most predominantly the quadriceps and finger flexors. ${ }^{3}$ The pathophysiology of IBM is not well understood, but two categories of histopathological features are characteristic of this disease, suggesting inflammatory (the myositis) and degenerative (inclusion body) mechanisms. ${ }^{1}$ Patients with IBM present with highly differentiated effector CD8+ T cells in their peripheral blood ${ }^{4-6}$ that invade muscle tissues ${ }^{5,7}$ as well as systemic CD4+FoxP3+ regulatory T-cell (Treg) deficiency. ${ }^{4}$ IBM patients are markedly associated $\left(p<10^{-33}\right)$ with HLA-DRB1, an autoimmune haplotype. ${ }^{8}$ They may also demonstrate anti-cN1A antibodies. ${ }^{9}$ Nonetheless, classical immunosuppressants are ineffective, and today, there are no recommendations for pharmacological approaches to treating IBM. ${ }^{3}$ However, the identification of amyloid deposits raised the possibility that IBM may be a primary degenerative muscle disorder. ${ }^{10}$ Actually, more than 80 distinct proteins have been found to aggregate ${ }^{11}$ (e.g., amyloid- $\beta$ precursor protein (AßPP); $A \beta 40$ and $A \beta 42$, and $A \beta 42$ oligomers $^{10}$ ) in some muscle fibers. Mitochondrial pathology is also frequently encountered. ${ }^{12}$ Finally, autophagy is compromised,${ }^{13}$ leading to the formation of p62/SQSTM1 aggregates. IBM is also considered to be a proteinopathy, similar to Alzheimer's disease.

Sirolimus (also called rapamycin) is an inhibitor of the mammalian target of rapamycin (mTOR) pathway, which is a major signaling pathway that integrates the availability of nutrients and growth factors in cell metabolism. ${ }^{14}$ The inhibition of mTOR exerts pleiotropic effects on cell metabolism by improving autophagy ${ }^{15}$ or mitochondrial functions. ${ }^{16}$ Sirolimus is the only drug that improves survival duration in mammals, ${ }^{17}$ and it also promotes survival and achieves better cognitive function in murine models of Alzheimer's disease. ${ }^{18}$ Furthermore, sirolimus is an immunosuppressant drug used to prevent organ transplant rejection, mostly in kidney 
transplantation. Interestingly, sirolimus promotes the differentiation and expansion of Tregs, ${ }^{19}$ and suppresses CD8+ and CD4+ effector T-cell populations. ${ }^{20}$

In this pilot study, we tested the efficacy of sirolimus in IBM patients.

\section{Methods}

\section{Study design}

This randomised, double-blind, placebo-controlled, proof of concept study was conducted at a single site (National Reference Center for Neuromuscular Rare Diseases of Paris, Centre investigation Clinique Paris Est, CIC 1421, at Pitié-Salpêtrière University Hospital, France). The study comprised a 15-day screening period (Days -15 to 0) and a 52-week treatment period (Day 0 to Month 12, referred to as D0 and M12). It was granted approval by the local Ethics Committee in April 2015 (\#3254), authorized by the French authorities (ANSM \#150241A-32, EudraCT \#2013-003485-14), and registered at ClinicalTrials.gov (NCT 02481453). This study conformed to the Declaration of Helsinki, and all study participants gave their informed, written consent to participation, in line with French ethical guidelines. This study conformed with the CONSORT 2010 Statement.

\section{Patients}

The study population included men and women (aged 45-80 years, inclusive) with a defined diagnosis of IBM according to established criteria. ${ }^{21}$ The study participants had to be able to walk at least $10 \mathrm{~m}$ without assistance from another person. The use of external assist devices (e.g., canes, walkers, or rollators) was permitted during the tests. Exclusion criteria were quadriceps weakness evaluated during manual muscle testing using the modified MRC scale 22 $\leq 1$, forced vital capacity (FVC) and/or a forced expiratory volume in 1 second (FEV1) $<50 \%$ of the predicted value, comorbidities other than IBM that significantly impacted the participants' mobility, the use of concomitant medications with an immunomodulatory effect or biological 
effect on muscle anabolism or catabolism, any active chronic disease associated with cachexia or muscle atrophy other than IBM, and any other uncontrolled medical condition that could limit the ability of the subject to participate in the study procedures. In addition, all patients were encouraged to practice a half hour of gentle physical exercise every day, in the form of a physiotherapy session, self-programming...

\section{Randomisation and masking}

Eligible participants were randomly assigned (1:1) to receive once-daily oral sirolimus at a dose of $2 \mathrm{mg}$ or placebo. Follow-up assessments were performed on day 10 and after 1, 2, 3, 6, 9 and 12 months. Centralized balanced-block randomization (blocks of 4) was computergenerated without stratification (by an independent statistician using SAS Software). Clinical data were extracted from medical records, they were coded by independent clinical research associate and stored in an Excel files. An independent double entry was made by Clinical Study Technicians. A data management procedure and quality control of the clinical/biological data, the functional and imaging measurements were finally performed. The study sponsor, participants and investigators performing the assessments of muscle strength, functional capacities, muscle imaging and immunomonitoring were blinded to treatment assignment. Because of the side effect profile of sirolimus (e.g., canker sores), medical monitors (who were not also evaluators) were nonblinded, as were the pharmacists in charge of the treatment delivery and therapeutic drug monitoring. Sirolimus levels were measured at each follow-up visit. The results of these tests were revealed only to the medical monitors, who made recommendations for dosage adjustment to maintain the sirolimus level between 4 and $10 \mathrm{ng}$ per milliliter. A corresponding sham dose adjustment was performed in the placebo group to maintain blinding (Supplementary table 1).

\section{Procedures and outcomes}

The primary endpoint was the relative percentage change from baseline to M12 of the maximal voluntary isometric knee extension strength, measured by a robotic computerized 
dynamometer (Biodex, Shirley, NY) according to strict standardized operating procedures. ${ }^{23}$ Maximal isometric knee extension strength was measured on both sides, and the primary endpoint was the mean of these two measures. Secondary endpoints included the following assessments at M6 and/or M12: 6-minute walk distance (6MWD); isometric muscle strength for hand grip (finger flexors), knee flexion and elbow flexion and extension; ${ }^{23}$ force vital capacity (FVC); muscle fat replacement measured by quantitative nuclear magnetic resonance imaging (qNMRI, see below); IBM Weakness Composite Index (IBMWCI) ${ }^{3}$ IBM Functional Rating Scale (IBMFRS);24 Health Assessment Questionnaire without Disability Index (HAQ-DI); and analyses of T cell subpopulations by mass cytometry. ${ }^{25}$ All functional data were expressed as percentages of predicted values for age, sex, weight or height.

To evaluate swallowing difficulties at the main visits (D0, M6 and M12), the patients were questioned for their swallowing troubles (yes or no), the presence of alimentary wrong way (yes or no), the presence of nasal regurgitation (yes or no), the presence of modification of their voice and finally they performed the glass of water drink test (duration in sec. to drink 100 $\mathrm{ml}$ of water).

Quantitative water-fat NMRI was performed using a 3D gradient echo (3-point Dixon) sequence on a 3-T clinical system (Prisma Fit, Siemens Healthineers, Erlangen, Germany). The lower limbs were immobilized by a customized leg-holder to facilitate reproducible repositioning between the baseline and M12 visits. Regions of interest were drawn manually on five slices on the out-of-phase Dixon images of the global muscle segments (leg and thigh) (Supplementary figure 1). For the thighs, the center slice was positioned at one-third of the length between the upper edge of the patella and the anterior-superior iliac spine (at midfemur), whereas for the legs, the stack of slices was centered at the thickest part of the leg. Segmentation and data processing were performed utilizing specifically written python code (CRIS, Tournai, Belgium). 
Using the Dixon images, fat fraction (FF) values were computed as the ratio between the fat signal and the sum of the water and fat signals (calculated as the weighted average of five slices). Disease progression was evaluated using the 1-year changes in FF ( $\triangle F F=F F M 12-$ FFD0, in \%) and was analyzed for the legs and thighs separately. Detailed information on radiofrequency coil configuration, MRI sequence parameters, subject positioning and data processing were described in our earlier published works. ${ }^{26,27}$

For the mass cytometric experiments, the barcoding, mass cytometric staining, data acquisition, data preprocessing (gating out of beads and dead cells) and statistical analyses were performed as previously described in a technical research article ${ }^{25}$ and for IBM patients. ${ }^{6}$ The list of antibodies used in this study is available in Supplementary table 2.

Safety was assessed by recording adverse events (AEs) throughout the study with additional measures that included physical examination, vital signs monitoring, hematology and blood chemistry tests, and CT scans.

\section{Statistical analysis}

The study was planned to enroll 44 participants (22 per group). The assumptions used for sample size calculations were based on observational data. ${ }^{23,28}$ We assumed that the relative change in knee extension strength (expressed as a percentage of the predicted values) at M12 would be $-17 \%(s d=16 \%)$ in the placebo group. We expected that the mean change observed in the patients treated with sirolimus would be $0 \%$ with the same variance. A two-sided test with a power of 0.85 and a type I error rate of 0.05 estimated that 18 patients were needed per group to show whether there is a statistically significant difference between the two groups (nQuery Advisor 4.0). Assuming that an estimated $10 \%$ of patients would be lost to follow-up, 22 patients were finally included in each group.

The analysis was performed on the intent-to-treat population. Qualitative variables are reported as frequencies, and quantitative variables are reported using median and inter-quartile range. Comparisons between both study arms were performed using nonparametric tests (Fisher's 
test for qualitative variable and the Mann-Whitney Wilcoxon test for quantitative variables). When data were missing, a conservative approach was applied considering the worse rank of the missing data in the Mann-Whitney Wilcoxon test. Endpoints between baseline (D0) and M12 were compared using the Wilcoxon paired test. The confidence interval for the difference in medians between the groups was estimated using bootstrap (5000 replications). Post hoc analyses were added to highlight the treatment effect on 6MWD. We used an ANCOVA mixed model with a random effect in patients.

Mean changes from baseline was analyzed using a restricted maximum likelihood (REML)based repeated measures approach in combination with the Newton Raphson Algorithm. Analyses included the fixed, categorical effects of treatment, visit, and treatment-by-visit interaction, as well as the continuous, fixed covariates of baseline score. A common unstructured covariance structure was used to model the within-patient errors. If this analysis fails to converge, the following structures were tested in a subsequent order until modelconvergence is achieved: autoregressive process of order 1 and then compound symmetry structure corresponding to a constant correlation. The Kenward-Roger approximation will be used to estimate denominator degrees of freedom. Significance tests were based on leastsquares means using a two-sided $\alpha=0.05$ (two-sided 95\% confidence intervals). Analyses

were implemented using $R$ software version $3 \cdot 3 \cdot 2$, package nlme, and checked by an independent statistician using SPSS version 22. The primary treatment comparisons were the contrast between treatments at the endpoint visit. Correlations have been assessed with the Pearson's correlation coefficient. Despite many secondary endpoints have been analyzed, no allowance for multiplicity has been done.

\section{Role of the funding source}

The funder of the study had no role in study design, data collection, data analysis, data interpretation, or writing of the report. The corresponding author had full access to all the data in the study and had final responsibility for the decision to submit for publication. 


\section{Results}

Between July 15, 2015 and May 13, 2016, a total of 285 patients were screened, of which 44 were randomly allocated to the treatment groups in this study (figure 1). A total of 22 patients received sirolimus, and 22 received placebo. Overall, $53 \%$ of the patients were male. All patients had preserved ambulatory capacity; the median (Q1-Q3) predictive value for 6MWD was $71 \%(55 \cdot 9-88 \cdot 11)$, the median (Q1-Q3) predictive value for knee extension strength (i.e., quadriceps) was $14.9 \%(7 \cdot 9-25 \cdot 1)$ and $27 \cdot 2 \%(19 \cdot 0-42 \cdot 3)$ for grip strength. None of the patients had received immunosuppressive or immunomodulatory drugs at inclusion. At baseline, there was no statistically significant difference between the groups (table 1 and Supplementary table 3), included on the swallowing parameters.

\section{Efficacy}

For the primary endpoint (i.e., the measure of knee extension strength), the difference between the sirolimus and placebo groups at M12 was not statistically significant (median difference $3.7895 \% \mathrm{Cl}[-10 \cdot 61 ; 17 \cdot 31], \mathrm{p}=0.85$, table 2 , supplementary figure 2$)$. This strength was statistically significantly lower in both groups after one year of follow-up than at baseline (sirolimus $-7 \cdot 8 \%, p=0 \cdot 0142$; placebo group $-11 \cdot 6 \%, p=0 \cdot 0019$ ).

Similarly, for other muscle strength measurements, i.e., grip, elbow flexion, elbow extension and knee flexion, strength tended to decline more in the placebo group than in the sirolimus group, but the differences between the groups were not statistically significant (table 2, supplementary figure 2). Regarding the swallowing difficulties, for each of the tested parameters and at every visit (D0, M6 or M12), no statistical differences were observed between the sirolimus group vs. the placebo group. At M12, the results of the self-administered questionnaire IBM-FRS and the functional scale IBMWCI medians were higher in sirolimus group than placebo group without being statistically significant (median difference 7.43 [-0.16; 14.29] and $9 \cdot 60[-1 \cdot 79 ; 27 \cdot 28]$ respectively). A statistically significant difference was observed 
in the disability scale HAQ-DI (median difference: $-0.27[-0.44 ;-0.01])$ : the mild disability scale was higher at M12 in the placebo group but remained stable in the sirolimus group (supplementary figure 2). Similarly, the FVC remained stable in the sirolimus group but was statistically significantly lower in the placebo group, and the difference became statistically significant at M12 (median difference $7 \cdot 72$ [1.36; 13.22], supplementary figure 2).

Regarding 6MWD, we observed that the difference was statistically significant at M12, when the median difference was $11.495 \% \mathrm{Cl}[0.36 ; 20 \cdot 86])(p=0.009$, supplementary figure 2$)$. The relative change in predictive distance remained stable in the sirolimus group (median: 1.69\% $(-7 \cdot 33-5 \cdot 32))$ but significantly decreased in the placebo group (median: $-9 \cdot 69 \%(-19 \cdot 5--2)$ ). Figure 2 illustrates the treatment effect on the 6MWD.

At M6, none of these parameters were statistically significant except the HAQ-DI $(p=0.043)$ and the 6MWD already seems to differ between groups at M6 (0.18 in Sirolimus group versus $-6 \cdot 78$ in Placebo group, $p=0 \cdot 07$, supplementary table 4 , supplementary figure 2 ).

Muscle fat replacement, when evaluated by qNMRI, demonstrated that at M12, the global thigh FF had increased by $1.42 \%(0 \cdot 11-2 \cdot 26)$ and $3.27 \%(1 \cdot 69-5 \cdot 16)$ in the sirolimus and placebo groups, respectively $(p=0.016)$. The global leg FF decreased by $-0.01 \%(-0.27-1.66)$ and increased by $1.36(0.29-1.33)$ in the sirolimus and placebo groups, respectively $(p=0.055)$ (Supplementary figure 3).

A correlation between relative change from baseline of 6MWD and change from baseline of FF in thigh and leg was observed in the placebo group only (Supplementary figure 4).

Finally, we performed single cell profiling of peripheral blood mononuclear cells (PBMCs) in the 44 patients at D0 and M12. Using CCR7 and CD45RA, we distinguished four main CD8 cells subsets. The activation status of these cell subsets was compared between sirolimus and placebo groups. We observed a decrease in activated $T$ effector memory cells $\left(T_{E M}\right)$ expressing the activation markers CD38 and HLA-DR under sirolimus (CD8+ $T_{E M}$ CD38+: sirolimus D0 vs. M12, $p=0.005$; and sirolimus $M 12$ vs. placebo $M 12, p=0.03$; and CD8 $+T_{E M}$ 
HLA-DR+: sirolimus D0 vs. M12, $p=0.2$; and sirolimus $M 12$ vs. placebo $M 12, p=0.02$ ). Interestingly, we also observed that the expression of CD38 in a previously identified activated CD8+ T cell population decreased during the course of IBM: CD8+ T-bet+ CD57- (sirolimus D0 vs. $M 12, p=0.003$; and sirolimus $M 12$ vs. placebo $M 12, p=0.01$ ) (Supplementary figure 5). For two of these CD8 subpopulations, their decline due to sirolimus was correlated with a better walked distance (Supplementary figure 6).

\section{Safety}

Ten patients (45\%) presented a serious side effect in the sirolimus group, whereas $6(27 \%)$ did so in the placebo group (table 3). These serious side effects were most frequently related to sirolimus (10 times over 18 episodes, table 3 ). Four patients in the sirolimus arm have to stop definitively their treatment (for severe mouth ulcers, aseptic pneumonia, renal insufficiency and peripheral lower limb edema). Severe mouth ulcers, aseptic pneumonia and peripheral lower limb edema, all related to sirolimus, resolved after its discontinuation. The canker sores were the most frequent side effects but remained mild or moderate (all grade 1 or 2 except 2 grade 3 episodes in one patient). In all, 40 episodes in 10 patients were reported in the sirolimus group, while 1 was reported in the placebo-treated patients.

\section{Discussion}

This randomised double-blind controlled proof of concept trial compared the efficacy of sirolimus against placebo in IBM patients and do not achieve to demonstrate a benefit in the primary outcome measure or general muscle strength in all other measured muscle groups but that benefits were achieved in other secondary endpoints (6MWD, FVC, HAQ, and FF as well as a trend in IBMWCI and IBMFRS). Our data suggest that sirolimus allowed sustainable walking ability and stabilized respiratory muscle function, which can be severely impacted by disease progression. ${ }^{3,29}$ 
This proof of concept trial also emphasizes the difficulty of choosing an appropriate outcome measure in IBM to use as a primary endpoint. In our study, the choice of knee extension strength was motivated by several considerations. First, this variable was the most prone to change during a natural history study in 16 patients. ${ }^{23}$ Second, the main purpose of a muscle is to generate force, and we therefore thought that the efficacy of sirolimus therapy could be first detected as changes in strength measurements and thereafter translated into improvement in motor functional abilities. Third, the relationship between force and function is known to be nonlinear, and sensitivity to changes in both dimensions is not the same across patients, in whom it depends on clinical status. ${ }^{28}$ We observed that in IBM patients quadriceps strength is considered a continuous variable of interest that is not limited by floor and ceiling effects. ${ }^{28}$ It is worth noting that quadriceps strength above $40 \%$ of the predictive normal value has been associated with a 6MWD ceiling effect, limiting its potential as a relevant outcome measure in stronger patients. ${ }^{28}$ Nonetheless, in our study, all the included patients were in relatively severe condition at study entry, with quadriceps strength below this $40 \%$ threshold (median quadriceps strength at $16 \%$ of predicted normal value). Our results suggest that in severely impaired IBM patients, 6MWD may be more sensitive than muscle strength measurements to changes. In the largest randomised controlled trial performed to date, which included 251 IBM patients and compared bimagrumab to placebo, ${ }^{30}$ the 6 MWD was the primary endpoint, but no effect of the treatment was observed after one year. ${ }^{30}$

The effect of sirolimus may be more pronounced on endurance than on muscle strength, as captured by the IBMWCI scale, the FVC or the 6MWD. Since the 6MWD is a global test, involving muscle strength, cardio-respiratory capacity, metabolic efficiency, and obviously patient cooperation and motivation, the improvement in the 6MWD could be explained by an improvement of the respiratory function. Other muscles involved in gait could be also improved like hip or ankle extensors, but their strength was not measured. However, the fact that none of the strength measurements improved does not favor this hypothesis. We already observed in a natural history study that the 6MWD was highly correlated to ankle extension and knee 
flexion and extension strength. ${ }^{23,28}$ However, muscle strength is not the only predictor of the walking ability measured during the 6MWD. As a first conclusion, sirolimus treatment may not act directly on the muscle itself but rather on other mechanisms improving the respiratory or metabolic status of the patients.

Improvements in the sirolimus arm were also corroborated by the finding that the results obtained on the HAQ-DI scale were better and the thigh and leg muscle FF observed on qNMRI lower in patients treated with sirolimus. Furthermore, the FF increase in the placebo group correlated well with the 6MWD decline. Indeed, in this study, quantitative fat-water NMRI clearly illustrated its value as an outcome measure for objectively assessing the differences in disease progression between untreated and treated patients. There is interest in qNMR because it is less dependent on patient cooperation and motivation but is sufficiently sensitive to measure treatment effects, even in small and highly heterogeneous patient populations. ${ }^{31}$ In a longitudinal natural history study of 20 IBM patients, ${ }^{31}$ Morrow et al. showed that qNMR measures changed statistically significantly during the 12-month follow-up period in both thigh and leg muscles. These changes were similar to what we observed in our placebo group (thigh level $+3 \cdot 3 \%$ vs. $+3 \cdot 3 \%$ in our study and leg level $+2 \cdot 6 \%$ vs. $+1 \cdot 4 \%$ in our study). ${ }^{31}$ Furthermore, similar to our study, in Morrow's study, NMR-measured FF showed greater responsiveness than either clinical or myometric measures. ${ }^{31}$

Human CD8+ T cells in peripheral blood are heterogeneous and can be divided into four main sub-populations according to their level of surface expression of CCR7 and CD45RA : $C C R 7^{\text {high }} C D 45 R A^{\text {high }}$ naïve phenotype $\left(T_{N}\right), C C R 7^{\text {high }} C D 45 R A^{\text {low }}$ central memory $\left(T_{C M}\right)$ phenotype, CCR7 ${ }^{\text {low }} C D 45 R A^{\text {low }}$ effector memory $\left(T_{E M}\right)$ phenotype, and CCR7 low $C D 45 R A^{\text {high }}$ CD8+ $T$ cells that are considered to be terminally differentiated memory cells $\left(T_{\text {EMRA }}\right) .{ }^{32}$ Using mass cytometry, ${ }^{6}$ we showed that the percentages of blood-activated CD8 T cells were lower in the sirolimus group. This observation was characterized by reduced frequencies of CD38+ 
and HLA-DR+ $T_{E M}$ cell populations. Actually, we previously showed that the frequencies of CD38+ and HLA-DR+ activated nonsenescent CD8 cells (CD8+ T-bet+ CD57- cells) which are $\mathrm{T}_{\mathrm{EM}}$ cells obtained from PBMCs were higher in IBM patients than in healthy donors. ${ }^{6}$ Interestingly, the proliferative responses of and IFN-y production by $\mathrm{T}_{\mathrm{EM}}$ cells were greatly inhibited when they were activated in vitro in the presence of rapamycin. ${ }^{33}$ Here, we showed that these activated cell subsets were decreased in the blood by sirolimus. We previously observed that both blood and muscle T cells expanded in IBM, ${ }^{7}$ suggesting that $\mathrm{T}$ cell blood phenotypes could be related to muscle phenotypes. We are well aware that this is an indirect measurement of the CD8 T muscle effector cells and that ideally an evaluation of these directly in the muscle biopsies performed before and after the initiation of the sirolimus treatment would have been preferable. But the knowledge of sampling bias in muscle biopsies (i.e. inflammatory infiltrates can vary considerably from one biopsy fragment to another for samples taken on the same day and in the same muscle), the practical difficulty of performing 2 biopsies (at D0 and M12) in 44 patients, the unfavourable opinion of the patients to undergo these 2 biopsies, has ethically not allowed us to propose these biopsies to the patients. We therefore opted for this indirect measurement of T effector cells but more integrative by the measurement and monitoring of $\mathrm{T}$ lymphocyte subclasses in peripheral blood. Taken together, these results suggest that different CD8+ effector cell populations are affected by sirolimus.

Sirolimus has potential metabolic and anti-inflammatory action. The latter was observed here since the CD8+ effector cell sub-populations had decreased under treatment and this decrease was correlated with maintaining the distance travelled. The metabolic effect was probably also present in the form of FF preservation, which was well correlated with the decline in distance travelled in the placebo group.

The safety profile of sirolimus has been extensively described because this drug has been commercialized for over 25 years. No unexpected side effects were observed in IBM patients treated with sirolimus. Nevertheless, it is important to note that $4 / 22$ patients discontinued 
treatment prematurely due to serious adverse events. However, we believe there is sufficient overall evidence of benefit in a sufficient proportion of patients to pursue a multicentric phase III trial to further assess its safety and efficacy.

Limitations of this study include the single centre recruitments of the patients, the short study duration over solely 52 weeks, and that from its conception the trial has been undersized to show an effect size of $0.3 .{ }^{34}$ Actually, the targeted difference in the sample size calculation was $17 \%$, with a common standard deviation of $16 \%$ corresponding to an expected standardized effect size of 1.06. But, the standardised effect observed on the primary endpoint was 0.62 . Thus, to size a pivotal study on this outcome with significant power, it would require a larger number of subjects.

Nevertheless, this pilot phase IIb study provides proof of concept results that support the potential efficacy. These findings need to be confirmed in a larger multicentric phase III trial and suggest that such a trial need to be performed using a different primary outcome measure (e.g., 6MWD or qNMR).

\section{Research in context}

\section{Evidence before this study}

We searched PubMed for blinded placebo-controlled trials published in English or French between Jan 1, 1960, and Jan 1, 2020, with the search terms "inclusion body myositis", OR "IBM". We also searched for "rapamycin", OR "sirolimus" AND IBM.

\section{Added value of this study}

We found only six trials (testing intravenous immunoglobulins (IVIG) with and without prednisone, methotrexate, IFN $\beta$, oxandrolone (for review ${ }^{1}$ ) and bimagrumab ${ }^{30}$ ). Except the last study ${ }^{30}$ which was conducted on 251 patients followed-up for 52 weeks, previous studies had a limited number of patients followed over short periods of time. This situation was 
inappropriate for the IBM, which has significant muscle deficit variability and whose natural history is often slowly progressive. In addition, the outcome measures (due to lack of international consensus) varied widely from one study to another, making interpretation of the results all the more difficult. Whatever the case may be, none of the primary outcome measures of these different trials have shown statistically significant differences between the therapeutic and the placebo. One IVIG trial out of the three have shown some improvement in swallowing function. Oxandrolone (an anabolic steroid with myotrophic properties) have shown upperextremity maximal voluntary isometric contraction testing improvement. Self-reported physical function score were improved in the arm with highest dose of bimagrumab. ${ }^{30}$ Nonetheless, there are today no recommended drugs for the treatment of IBM which is an important unmet need for the patients.

This study is the only one testing sirolimus and the first 52 -week randomised, double blind, clinical study to assess the efficacy, safety, and tolerability of sirolimus at $2 \mathrm{mg} / \mathrm{day}$, compared with placebo in patients with until now untreatable IBM. The 6MWD as well as the muscle fatty replacement evaluated by qNMR remained stable in the sirolimus group rather than it respectively statistically significantly decrease and increase in the placebo group. Sirolimus was generally well tolerated, with most treatment-emergent adverse events rated as mild or moderate in severity. For every severe side-effects, sirolimus withdrawal permitted their remission.

\section{Implications of all the available evidence}

This single centre, randomised, placebo-controlled, proof of concept study provides efficacy, safety, and tolerability data for sirolimus for patients with uncontrolled IBM. Even if no benefit was achieved in the primary outcome measure or general muscle strength in all other measured muscle groups (because the study was underpowered to show reasonable effect size $^{34}$ but benefits were achieved in the majority of other secondary endpoints (6MWD, FVC, $\mathrm{HAQ}, \mathrm{FF}$ and CD8 T effector cell decline as well as a trend in IBMWCI and IBMFRS) among 
which certain are robust such as the FF since not related to measure variation, the will of patients, nor clinician interpretation. All these results encourage us to carry out a confirmatory multicentric phase III trial.

\section{Contributors}

$\mathrm{OB}, \mathrm{SAG}$, and YA wrote the first draft. LB, and MA contributed to the statistical analyses. JYH, LB, HR and PGC prepared the figures. DB, AR, PL, GDT, JES, LSN, TS, NZ, BH, OLC, AB, EG, HR, DA, AU, KM, BM, BE, and JSH led the trial overall, and contributed to critical review and revision of the report.

\section{Declaration of Interest}

OB reports grants from Sanofi, personal fees from CSL-Behring, personal fees from LFB, personal fees from Novartis, personal fees from Ra-Pharma, outside the submitted work; . JYH reports personal fees from Biogen, personal fees from Sarepta, outside the submitted work; PL reports grants and personal fees from Genzyme-Sanofi, personal fees from Biogen, personal fees from Spark Therapeutics, outside the submitted work; JES reports personal fees from BMS, outside the submitted work; TS reports personal fees from Genzyme-Sanofi, personal fees from Biogen, personal fees from LFB, outside the submitted work; AB reports personal fees from Genzyme-Sanofi, personal fees from Ultragenyx Pharmaceutical, outside the submitted work; BE reports personal fees from Roche, personal fees from Alexys-Santé, outside the submitted work; PGC reports personal fees from Genzyme-Sanofi, personal fees from Sarepta, personal fees from Santhera, outside the submitted work; JSH reports grants from Leducq Foundation, outside the submitted work; SAG reports personal fees from Abcuro, outside the submitted work; YA reports grants from Sanofi, personal fees from Eli Lilly , personal fees from BMS, outside the submitted work; All other authors declare no competing interests.

\section{Aknowledgements:}


We would like to thank the team at the East-Paris Clinical Investigation Center for their careful evaluation of the patients throughout their year of follow-up. This project received grants: Appel à projet 2012 Inserm-DGOS "Recherche Clinique Translationnelle" \#A12035DS and AFM. 


\section{References}

1 Benveniste O, Stenzel W, Hilton-Jones D, Sandri M, Boyer O, van Engelen BGM. Amyloid deposits and inflammatory infiltrates in sporadic inclusion body myositis: the inflammatory egg comes before the degenerative chicken. Acta Neuropathol (Berl) 2015; 129: 611-24.

2 Keshishian A, Greenberg SA, Agashivala N, Baser O, Johnson K. Health care costs and comorbidities for patients with inclusion body myositis. Curr Med Res Opin 2018; 34: 1679-85.

3 Benveniste O, Guiguet M, Freebody J, et al. Long-term observational study of sporadic inclusion body myositis. Brain 2011; 134: 3176-84.

4 Allenbach Y, Chaara W, Rosenzwajg M, et al. Th1 response and systemic treg deficiency in inclusion body myositis. PloS One 2014; 9: e88788.

5 Greenberg SA, Pinkus JL, Kong SW, Baecher-Allan C, Amato AA, Dorfman DM. Highly differentiated cytotoxic T cells in inclusion body myositis. Brain J Neurol 2019; 142: 2590604.

6 Dzangué-Tchoupou G, Mariampillai K, Bolko L, et al. CD8+T-bet+ cells as a predominant biomarker for inclusion body myositis. Autoimmun Rev 2019; 18: 325-33.

7 Dimitri D, Benveniste O, Dubourg O, et al. Shared blood and muscle CD8+ T-cell expansions in inclusion body myositis. Brain 2006; 129: 986-95.

8 Rothwell S, Cooper RG, Lundberg IE, et al. Immune-array Analysis in Sporadic Inclusion Body Myositis Reveals HLA-DRB1 Amino Acid Heterogeneity across the Myositis Spectrum. Arthritis Rheumatol Hoboken NJ 2017; published online Jan 13. DOI:10.1002/art.40045.

9 Larman HB, Salajegheh M, Nazareno R, et al. Cytosolic 5'-nucleotidase 1A autoimmunity in sporadic inclusion body myositis. Ann Neurol 2013; 73: 408-18.

10 Askanas V, Engel WK. Inclusion-body myositis: a myodegenerative conformational disorder associated with Abeta, protein misfolding, and proteasome inhibition. Neurology 2006; 66: S39-48.

11 Greenberg SA. Theories of the Pathogenesis of Inclusion Body Myositis. Curr Rheumatol Rep 2010; 12: 221-8.

12Oldfors A, Moslemi AR, Jonasson L, Ohlsson M, Kollberg G, Lindberg C. Mitochondrial abnormalities in inclusion-body myositis. Neurology 2006; 66: S49-55.

13Lunemann JD, Schmidt J, Schmid D, et al. Beta-amyloid is a substrate of autophagy in sporadic inclusion body myositis. Ann Neurol 2007; 61: 476-83.

14Giguère V. Canonical signaling and nuclear activity of mTOR-a teamwork effort to regulate metabolism and cell growth. FEBS J 2018; 285: 1572-88.

15Kim YC, Guan K-L. mTOR: a pharmacologic target for autophagy regulation. J Clin Invest 2015; 125: 25-32. 
16Li Q, Zhang T, Wang J, et al. Rapamycin attenuates mitochondrial dysfunction via activation of mitophagy in experimental ischemic stroke. Biochem Biophys Res Commun 2014; 444: 182-8.

17Harrison DE, Strong R, Sharp ZD, et al. Rapamycin fed late in life extends lifespan in genetically heterogeneous mice. Nature 2009; 460: 392-5.

18Cai Z, Yan L-J. Rapamycin, Autophagy, and Alzheimer's Disease. J Biochem Pharmacol Res 2013; 1: 84.

19 Haxhinasto S, Mathis D, Benoist C. The AKT-mTOR axis regulates de novo differentiation of CD4+Foxp3+ cells. J Exp Med 2008; 205: 565-74.

20Delgoffe GM, Pollizzi KN, Waickman AT, et al. The kinase mTOR regulates the differentiation of helper T cells through the selective activation of signaling by mTORC1 and mTORC2. Nat Immunol 2011; 12: 295-303.

21Lloyd TE, Mammen AL, Amato AA, Weiss MD, Needham M, Greenberg SA. Evaluation and construction of diagnostic criteria for inclusion body myositis. Neurology 2014; 83: 426-33.

22 Vanhoutte EK, Faber CG, van Nes SI, et al. Modifying the Medical Research Council grading system through Rasch analyses. Brain J Neurol 2012; 135: 1639-49.

23Allenbach Y, Benveniste O, Decostre V, et al. Quadriceps strength is a sensitive marker of disease progression in sporadic inclusion body myositis. Neuromuscul Disord NMD 2012; 22: $980-6$.

24Jackson CE, Barohn RJ, Gronseth G, Pandya S, Herbelin L, Muscle Study Group. Inclusion body myositis functional rating scale: a reliable and valid measure of disease severity. Muscle Nerve 2008; 37: 473-6.

25Dzangué-Tchoupou G, Corneau A, Blanc C, Benveniste O, Allenbach Y. Analysis of cell surface and intranuclear markers on non-stimulated human PBMC using mass cytometry. PloS One 2018; 13: e0194593.

26Marty B, Baudin P-Y, Reyngoudt $\mathrm{H}$, et al. Simultaneous muscle water $\mathrm{T} 2$ and fat fraction mapping using transverse relaxometry with stimulated echo compensation. NMR Biomed 2016; 29: 431-43.

27Azzabou N, Loureiro de Sousa P, Caldas E, Carlier PG. Validation of a generic approach to muscle water T2 determination at 3T in fat-infiltrated skeletal muscle. J Magn Reson Imaging JMRI 2015; 41: 645-53.

28 Hogrel J-Y, Allenbach Y, Canal A, et al. Four-year longitudinal study of clinical and functional endpoints in sporadic inclusion body myositis: Implications for therapeutic trials. Neuromuscul Disord NMD 2014; published online May 4. DOI:10.1016/j.nmd.2014.04.009.

29Rodríguez Cruz PM, Needham M, Hollingsworth P, Mastaglia FL, Hillman DR. Sleep disordered breathing and subclinical impairment of respiratory function are common in sporadic inclusion body myositis. Neuromuscul Disord NMD 2014; 24: 1036-41.

30Hanna MG, Badrising UA, Benveniste O, et al. Safety and efficacy of intravenous bimagrumab in inclusion body myositis (RESILIENT): a randomised, double-blind, placebo-controlled phase 2b trial. Lancet Neurol 2019; 18: 834-44. 
31 Morrow JM, Sinclair CDJ, Fischmann A, et al. MRI biomarker assessment of neuromuscular disease progression: a prospective observational cohort study. Lancet Neurol 2016; 15: 65-77.

32Appay V, van Lier RAW, Sallusto F, Roederer M. Phenotype and function of human T lymphocyte subsets: consensus and issues. Cytom Part J Int Soc Anal Cytol 2008; 73: 975-83.

33Setoguchi R, Matsui $\mathrm{Y}$, Mouri K. mTOR signaling promotes a robust and continuous production of IFN-y by human memory CD8+ T cells and their proliferation. Eur J Immunol 2015; 45: 893-902.

34Rothwell JC, Julious SA, Cooper CL. A study of target effect sizes in randomised controlled trials published in the Health Technology Assessment journal. Trials 2018; 19: 544. 
Tables

\begin{tabular}{|c|c|c|}
\hline & $\begin{array}{c}\text { Sirolimus } \\
(n=22)\end{array}$ & $\begin{array}{c}\text { Placebo } \\
(n=22)\end{array}$ \\
\hline Male sex, no. (\%) & $12(55 \%)$ & $11(50 \%)$ \\
\hline \multicolumn{3}{|l|}{ Age, yr } \\
\hline At trial agent initiation & $68(63 \cdot 5-72 \cdot 3)$ & $66(58 \cdot 5-70 \cdot 5)$ \\
\hline At disease onset & $60(55-63 \cdot 8)$ & $58(48 \cdot 3-65)$ \\
\hline \multicolumn{3}{|l|}{6 MWD } \\
\hline$\%$ of predictive value & $76(69 \cdot 1-96 \cdot 2)$ & $65(51 \cdot 7-85 \cdot 4)$ \\
\hline \multicolumn{3}{|l|}{ Myometry } \\
\hline Grip strength ( $\%$ of predicted value) & $32 \cdot 1(26 \cdot 1-46 \cdot 8)$ & $24 \cdot 2(16 \cdot 6-32 \cdot 5)$ \\
\hline $\begin{array}{l}\text { Elbow flexion strength }(\% \text { of } \\
\text { predicted value })\end{array}$ & $32 \cdot 3(26 \cdot 8-44 \cdot 3)$ & $24.9(18.6-41 \cdot 6)$ \\
\hline $\begin{array}{l}\text { Elbow extension strength ( } \% \text { of } \\
\text { predicted value) }\end{array}$ & $42 \cdot 4(29 \cdot 2-59 \cdot 1)$ & $26 \cdot 4(16 \cdot 8-59 \cdot 0)$ \\
\hline $\begin{array}{l}\text { Knee flexion strength (\% of predicted } \\
\text { value) }\end{array}$ & $44 \cdot 5(32 \cdot 5-60 \cdot 1)$ & $34 \cdot 6(26 \cdot 6-62 \cdot 5)$ \\
\hline $\begin{array}{l}\text { Knee extension strength }(\% \text { of } \\
\text { predicted value) }\end{array}$ & $13 \cdot 1(9 \cdot 8-24)$ & $18 \cdot 6(6 \cdot 6-34 \cdot 4)$ \\
\hline FVC $(\%)$ & $109 \cdot 5(97 \cdot 3-121 \cdot 8)$ & $109(89 \cdot 8-115)$ \\
\hline FVC (L) & $3.54(2.48-4.49) \quad 0.90$ & $3 \cdot 28(2 \cdot 75-4 \cdot 24)$ \\
\hline IBMWCI (max 100) & $65(56 \cdot 3-75)$ & $60(55-75)$ \\
\hline IBMFRS (max 40) & $32 \cdot 5(30-34 \cdot 8)$ & $33(28 \cdot 3-34)$ \\
\hline
\end{tabular}




\begin{tabular}{|c|c|c|}
\hline HAQ-DI & $0.8(0.5-0.9)$ & $0.9(0.6,1.4)$ \\
\hline CK & $325 \cdot 5(230 \cdot 5-705)$ & $\begin{array}{l}455 \cdot 5(298 \cdot 5-77 \\
7 \cdot 3)\end{array}$ \\
\hline Anti-cN1A+ & $7(32 \%)$ & $9(41 \%)$ \\
\hline Leg global FF (\%) & $19 \cdot 9(16 \cdot 2-29 \cdot 4)$ & $\begin{array}{c}20 \cdot 5(16 \cdot 0- \\
32 \cdot 2)\end{array}$ \\
\hline Thigh global FF (\%) & $34.8(22.9-42 \cdot 1)$ & $\begin{array}{c}31 \cdot 1(21 \cdot 6- \\
36 \cdot 7)\end{array}$ \\
\hline \multicolumn{3}{|c|}{$\begin{array}{l}\text { * Quantitative data are expressed as medians (Q1-Q3). Qualitative data are expressed as N (\%). } \\
6 \text { MWD: } 6 \text { Min. Walking Distance } \\
\text { FVC: Force vital capacity } \\
\text { HAQ-DI: Health Assessment Questionnaire without Disability Index } \\
\text { IBMWCI: IBM Weakness Composite Index } \\
\text { IBMFRS: IBM Functional Rating Scale } \\
\text { CK: Creatine kinase } \\
\text { FF: Fat fraction measured by quantitative nuclear magnetic resonance imaging }\end{array}$} \\
\hline
\end{tabular}




\begin{tabular}{|c|c|c|c|c|}
\hline & $\begin{array}{l}\text { Sirolimus } \\
(n=22)\end{array}$ & $\begin{array}{l}\text { Placebo } \\
(n=22)\end{array}$ & $\begin{array}{c}\text { Difference } \\
{[95 \% \mathrm{Cl}]}\end{array}$ & $\begin{array}{c}p \\
\text { value }\end{array}$ \\
\hline \multicolumn{5}{|l|}{ Primary endpoint } \\
\hline $\begin{array}{l}\text { Knee extension } \\
\text { strength (\% change } \\
\text { at } \mathrm{M} 12)^{\mathrm{V}}\end{array}$ & $\begin{array}{c}-7 \cdot 8(-25 \cdot 2- \\
0 \cdot 75)\end{array}$ & $\begin{array}{c}-11.6(-25 \cdot 2-- \\
1.67)\end{array}$ & $\begin{array}{c}3 \cdot 78 \\
{[-10 \cdot 61} \\
17 \cdot 31]\end{array}$ & 0.85 \\
\hline \multicolumn{5}{|l|}{ Secondary endpoints } \\
\hline $\begin{array}{l}\text { Grip strength }(\% \\
\text { change at M12) }\end{array}$ & $\begin{array}{c}-4 \cdot 9(-13 \cdot 4- \\
1 \cdot 27)\end{array}$ & $\begin{array}{c}-12 \cdot 0(-20 \cdot 46- \\
10 \cdot 97)\end{array}$ & $\begin{array}{c}7 \cdot 13 \\
{[-4 \cdot 31} \\
18 \cdot 50]\end{array}$ & 0.19 \\
\hline $\begin{array}{l}\text { Elbow flexion } \\
\text { strength (\% change } \\
\text { at M12) })^{\delta}\end{array}$ & $-3(-5 \cdot 90-9 \cdot 30)$ & $\begin{array}{c}-14.4(-18 \cdot 1- \\
1.91)\end{array}$ & $\begin{array}{l}11 \cdot 37 \\
{[-4 \cdot 16} \\
21 \cdot 24]\end{array}$ & 0.27 \\
\hline $\begin{array}{l}\text { Elbow extension } \\
\text { strength (\% change } \\
\text { at } \mathrm{M} 12)^{\theta}\end{array}$ & $\begin{array}{c}-1 \cdot 89(-12 \cdot 9- \\
16 \cdot 5)\end{array}$ & $\begin{array}{c}-0.33(-12.9- \\
6 \cdot 8)\end{array}$ & $\begin{array}{c}-1.57 \\
{[-14.1 ; 16.8]}\end{array}$ & 0.82 \\
\hline $\begin{array}{l}\text { Knee flexion } \\
\text { strength (\% change } \\
\text { at M12) })^{\S}\end{array}$ & $\begin{array}{c}-11 \cdot 4(-28 \cdot 14- \\
2 \cdot 21)\end{array}$ & $\begin{array}{c}-14.5(-19 \cdot 11-- \\
9 \cdot 96)\end{array}$ & $\begin{array}{c}3 \cdot 14 \\
{[-14 \cdot 30} \\
10 \cdot 91]\end{array}$ & 0.93 \\
\hline $\begin{array}{l}\text { 6MWD (\% change } \\
\text { at M12) }\end{array}$ & $\begin{array}{c}1.69(-7 \cdot 33- \\
5 \cdot 32)\end{array}$ & $-9.69(-19 \cdot 5--2)$ & $\begin{array}{c}11 \cdot 37 \\
{[0 \cdot 36 ; 20 \cdot 86]}\end{array}$ & 0.009 \\
\hline $\begin{array}{l}\text { FVC (\% change } \\
\text { relative to D0) }\end{array}$ & $\begin{array}{c}2.4(-3 \cdot 60- \\
7 \cdot 65)\end{array}$ & $\begin{array}{c}-5 \cdot 26(-8 \cdot 80-(- \\
0 \cdot 45))\end{array}$ & $\begin{array}{c}7 \cdot 72 \\
{[1 \cdot 36 ; 13 \cdot 22]}\end{array}$ & 0.006 \\
\hline $\begin{array}{l}\text { FVC (\% change } \\
\text { relative to DO in } L)\end{array}$ & $\begin{array}{c}0.38(-4 \cdot 68- \\
6 \cdot 28)\end{array}$ & $\begin{array}{c}-5.95(-9.39-(- \\
1 \cdot 47))\end{array}$ & $\begin{array}{c}6 \cdot 33 \\
{[0 \cdot 44 ; 12 \cdot 49]}\end{array}$ & 0.009 \\
\hline $\begin{array}{l}\text { IBMWCI (\% change } \\
\text { at } \mathrm{M} 12 \text { from D0 })^{\varphi}\end{array}$ & $-11 \cdot 1(-20 \cdot 0-0)$ & $\begin{array}{c}-20 \cdot 7(-39 \cdot 09-- \\
8 \cdot 88)\end{array}$ & $\begin{array}{c}9 \cdot 60 \\
{[-1 \cdot 79} \\
27 \cdot 28]\end{array}$ & 0.082 \\
\hline $\begin{array}{l}\text { IBM-FRS }(\% \\
\text { change at M12 from } \\
\text { D0) }\end{array}$ & $\begin{array}{c}-1.39(-11 \cdot 89- \\
0)\end{array}$ & $\begin{array}{c}-8 \cdot 82(-17.80-- \\
2 \cdot 73)\end{array}$ & $\begin{array}{l}7 \cdot 43 \\
{[-0 \cdot 16} \\
14 \cdot 29]\end{array}$ & $0 \cdot 14$ \\
\hline $\begin{array}{l}\text { HAQ-DI } \\
\text { (Differences from } \\
\text { D0 to M12) }\end{array}$ & $\begin{array}{c}-0.05(-0.17- \\
0.30)\end{array}$ & $\begin{array}{c}0.22(0.05- \\
0.38)\end{array}$ & $\begin{array}{c}-0.27 \\
{[-0.44 ;-} \\
0.01]\end{array}$ & 0.035 \\
\hline $\begin{array}{l}\text { CK (Differences } \\
\text { from D0 to M12) }\end{array}$ & $-53(-112-97)$ & $-4(-124 \cdot 5-34 \cdot 5)$ & $\begin{array}{c}-49 \\
{[-99 ; 96]}\end{array}$ & 0.93 \\
\hline $\begin{array}{l}\Delta \mathrm{FF} \text { (global) in the } \\
\text { leg (Difference from } \\
\mathrm{D} 0 \text { to } \mathrm{M} 12)^{\varsigma}\end{array}$ & $\begin{array}{c}-0.01(-0.27- \\
1.66)\end{array}$ & $\begin{array}{c}1.36(0.29- \\
1.99)\end{array}$ & $\begin{array}{c}-1 \cdot 14[-1 \cdot 98 \\
0 \cdot 24]\end{array}$ & 0.055 \\
\hline $\begin{array}{l}\Delta \mathrm{FF} \text { (global) in the } \\
\text { thigh (Differences } \\
\text { from Do to M12) }\end{array}$ & $\begin{array}{c}1.43(0 \cdot 11- \\
2 \cdot 27)-\end{array}$ & $\begin{array}{c}3 \cdot 27(1.69- \\
5 \cdot 16)\end{array}$ & $\begin{array}{c}-1 \cdot 84[-3 \cdot 75 \\
-0 \cdot 40]\end{array}$ & 0.016 \\
\hline
\end{tabular}


Hypothesis tests used to compare sirolimus with placebo were performed with a conservative approach: the worse-case scenario as described in the Statistical Analysis section.

$\mathrm{Cl}$ : confidence interval

FVC: Forced vital capacity

IBMWCI: IBM weakness composite index

IBMFRS: IBM Functional Rating Scale

HAQ-DI: Health Assessment Questionnaire without Disability Index

CK: Creatine kinase

FF: Fat fraction

Table 2: Efficacy endpoints at M12. All analyses are performed in intention to treat.

Y Data were missing for one patient at M12 in the sirolimus group.

${ }^{\delta}$ Data were missing for one patient at M12 in the sirolimus group.

${ }^{\theta}$ Data were missing for one patient at M12 in each group.

$\S$ Data were missing for one patient at M12 in the sirolimus group.

$\varphi$ Data were missing for one patient at M12 in the sirolimus group.

$\varsigma^{\varsigma}$ Data were missing for one patient at M12 in the placebo group.

${ }^{\omega}$ Data were missing for two patients at M12 in the placebo group, and data were missing for one patient at M12 in the sirolimus group. 


\begin{tabular}{|c|c|c|c|c|}
\hline & Sirolim & $s(n=22)$ & Place & $(n=22)$ \\
\hline & No. of events & $\begin{array}{c}\text { No. of patients } \\
(\%)\end{array}$ & $\begin{array}{l}\text { No. of } \\
\text { events }\end{array}$ & $\begin{array}{l}\text { No. of } \\
\text { patients } \\
\text { (\%) }\end{array}$ \\
\hline Any adverse events & 207 & $22(100 \%)$ & 162 & $22(100 \%)$ \\
\hline Falls & 24 & $14(63.6)$ & 37 & $16(73)$ \\
\hline Canker sores & 40 & $10(45 \cdot 4)$ & 1 & $1(4 \cdot 5)$ \\
\hline Any serious adverse events & 18 & $10(45)$ & 8 & $6(27)$ \\
\hline Mouth ulcers* & 2 & $2(9)$ & 0 & 0 \\
\hline Aseptic pneumonia* & 4 & $2(9)$ & 0 & 0 \\
\hline Lower limb edema* & 4 & $3(13 \cdot 6)$ & 0 & 0 \\
\hline Renal insufficiency & 1 & $1(4 \cdot 5)$ & 0 & 0 \\
\hline Viral colitis & 1 & $1(4 \cdot 5)$ & 0 & 0 \\
\hline Depressive syndrome & 2 & $1(4 \cdot 5)$ & 0 & 0 \\
\hline Basal cell carcinoma & 1 & $1(4 \cdot 5)$ & 0 & 0 \\
\hline Fall-related fractures & 2 & $2(9)$ & 2 & $2(9)$ \\
\hline Nephrolithiasis & 1 & $1(4 \cdot 5)$ & 0 & 0 \\
\hline $\begin{array}{l}\text { Artery occlusive disease } \\
\text { of the lower limb }\end{array}$ & 0 & 0 & 3 & $1(4 \cdot 5)$ \\
\hline Coronary heart disease & 0 & 0 & 1 & $1(4 \cdot 5)$ \\
\hline $\begin{array}{l}\text { Transient ischemic } \\
\text { attack }\end{array}$ & 0 & 0 & 1 & $1(4 \cdot 5)$ \\
\hline
\end{tabular}


Hemoptysis

0

0

1

$1 \quad(4 \cdot 5$

*Adverse events related to sirolimus

Table 3: Summary of adverse events in the safety population 


\section{Legend to figures}

\section{Figure 1: Trial profile}

The intention-to-treat population and safety population included all patients randomly assigned to the treatment groups $(n=44)$. One eligible patient was enrolled but withdrawn from the trial before being assigned to a treatment group. ). Four patients in the sirolimus arm have to stop definitively their treatment for severe mouth ulcers, aseptic pneumonia, renal insufficiency and peripheral lower limb edema.

Figure 2: Least square relative change in the predicted 6-minute walk distance from baseline to month 12 in patients in the sirolimus $(n=22)$ and placebo $(n=22)$ groups in the intention-to-treat population.

Error bars show the standard errors. ANCOVA model based on the relative change from baseline as the dependent variable; independent variables included the treatment and baseline 6-minute walk distances as covariates. 


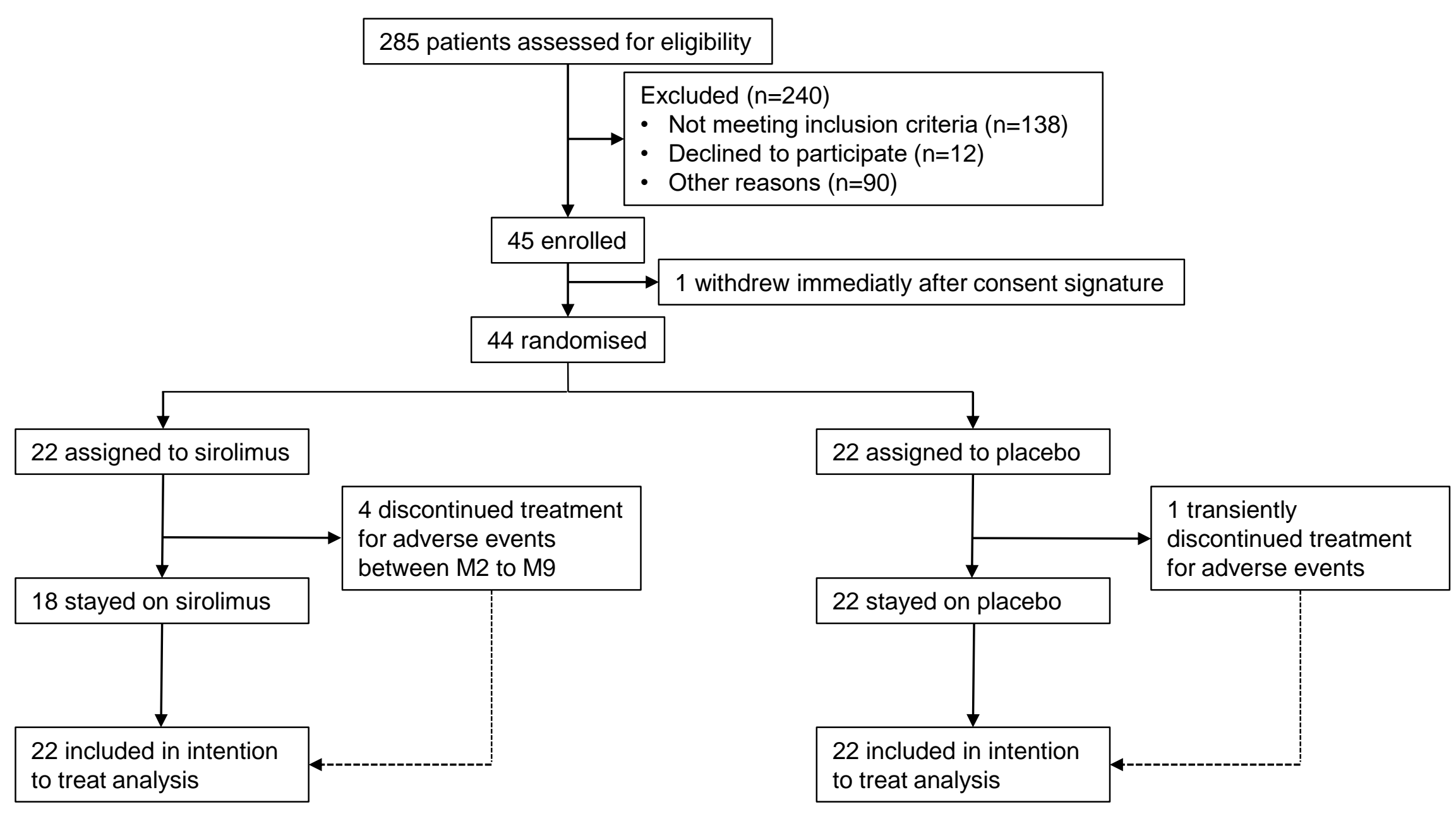




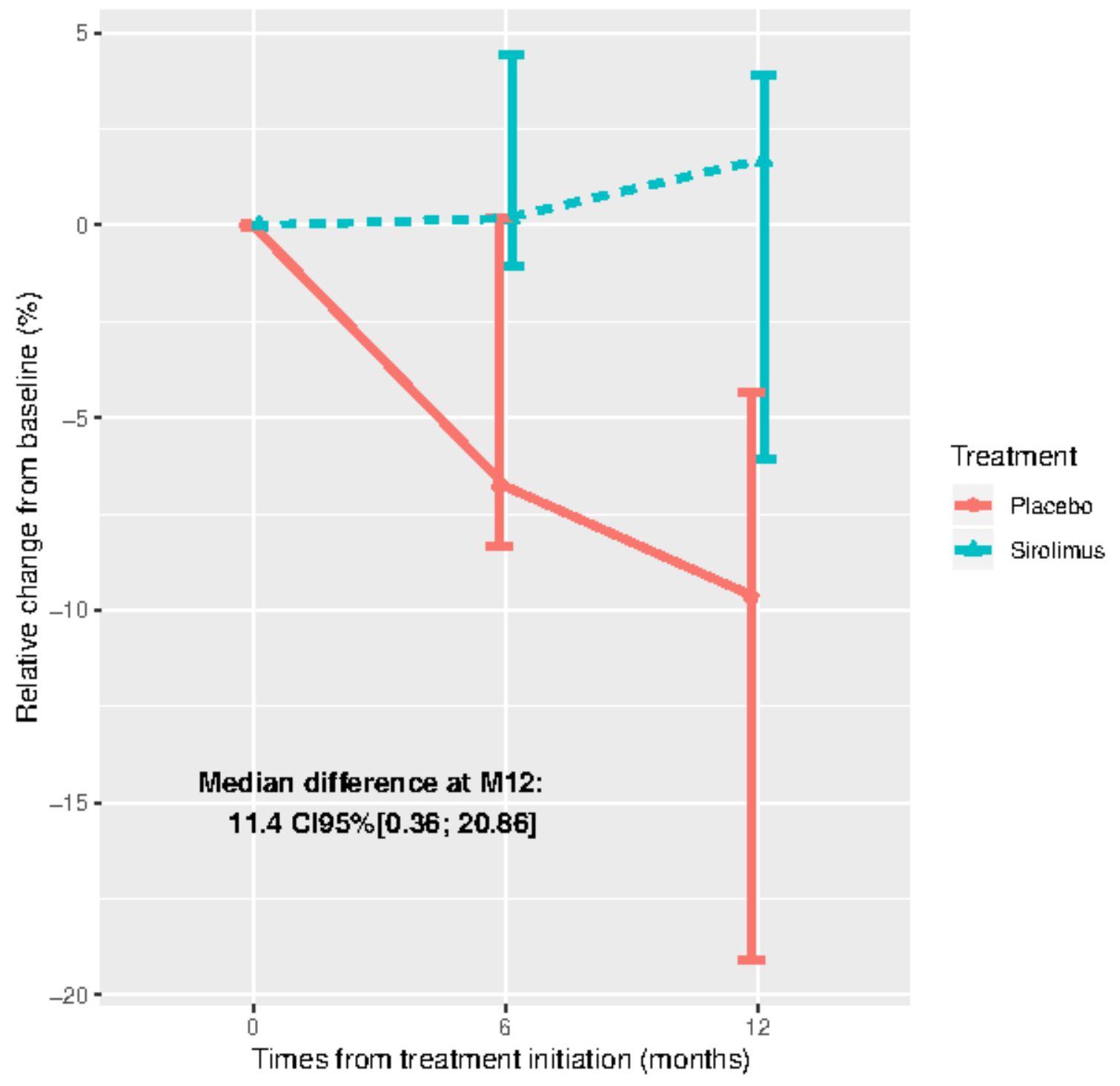




\section{Supplementary Figures}

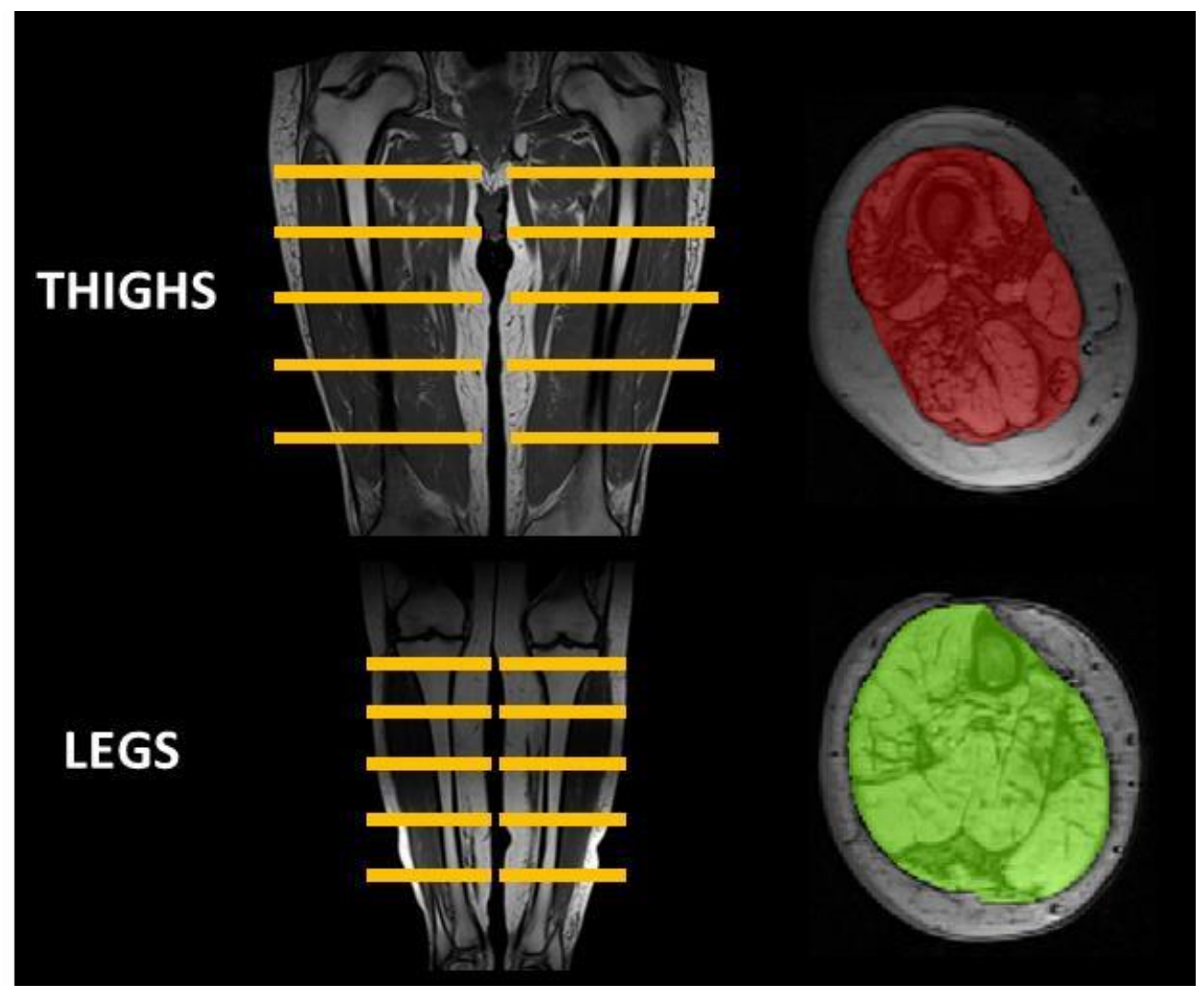

Supplementary Figure 1: Illustration of the positioning of the slices in the thighs and legs.

Example of how the regions of interest were drawn on the middle out-of-phase Dixon image of the whole segments (red: thigh; green: leg). 


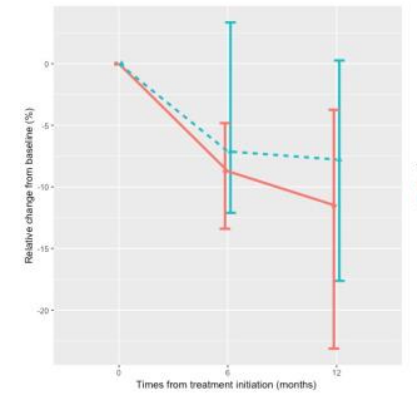

Knee extension strength

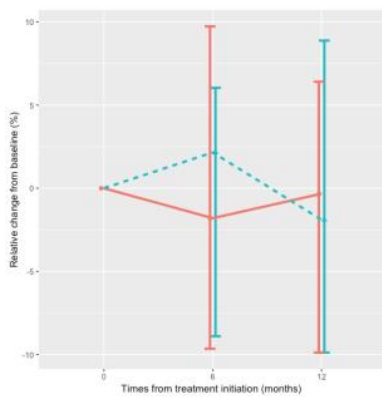

Elbow extension strength

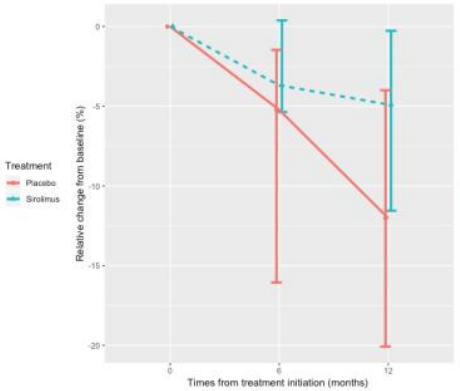

Grip strength

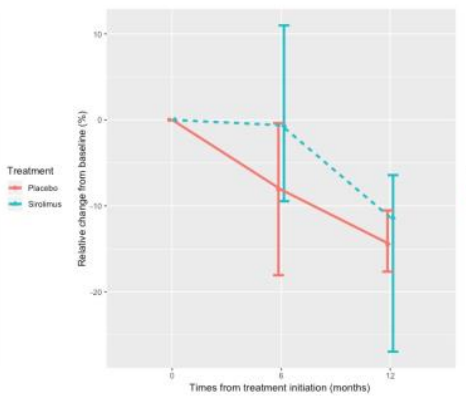

Knee flexion strength

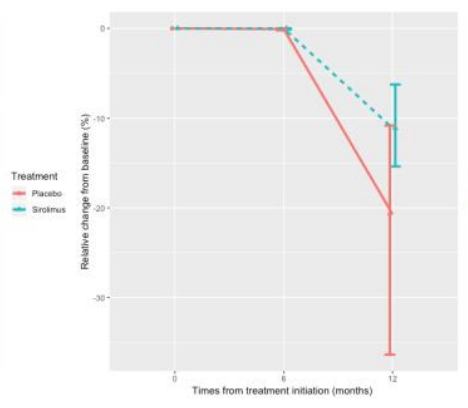

$\mathrm{IBMWCl}$

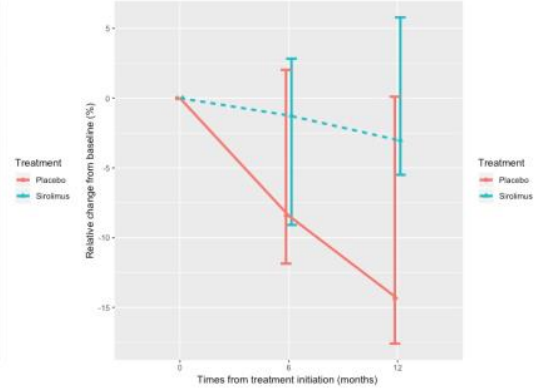

Elbow flexion strength

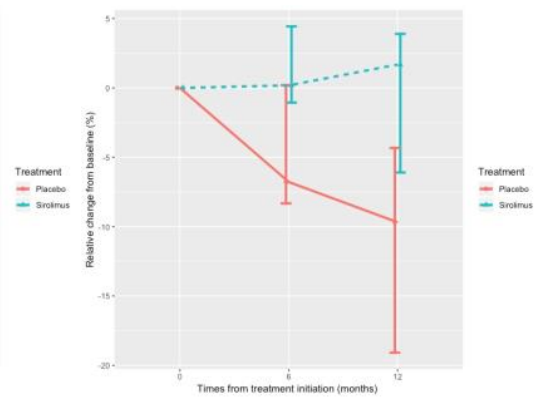

6MWD

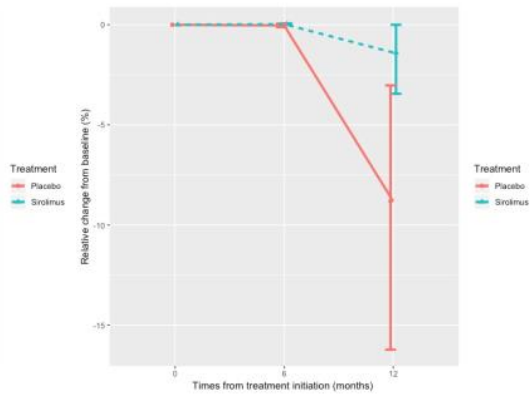

IBMFRS

FVC

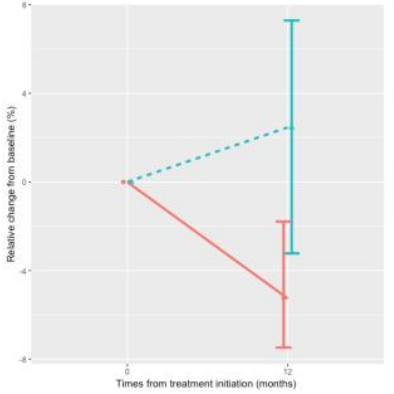

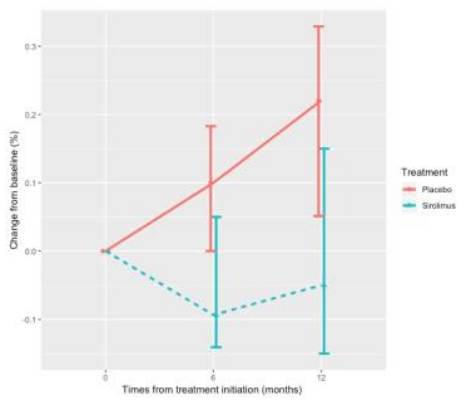

HAQ-DI

Supplementary Figure 2: Efficacy endpoints in the sirolimus $(n=22)$ and placebo $(n=22)$ groups in the intention-to-treat population.

Quantitative data are expressed as medians with their $95 \%$ confidence interval. 


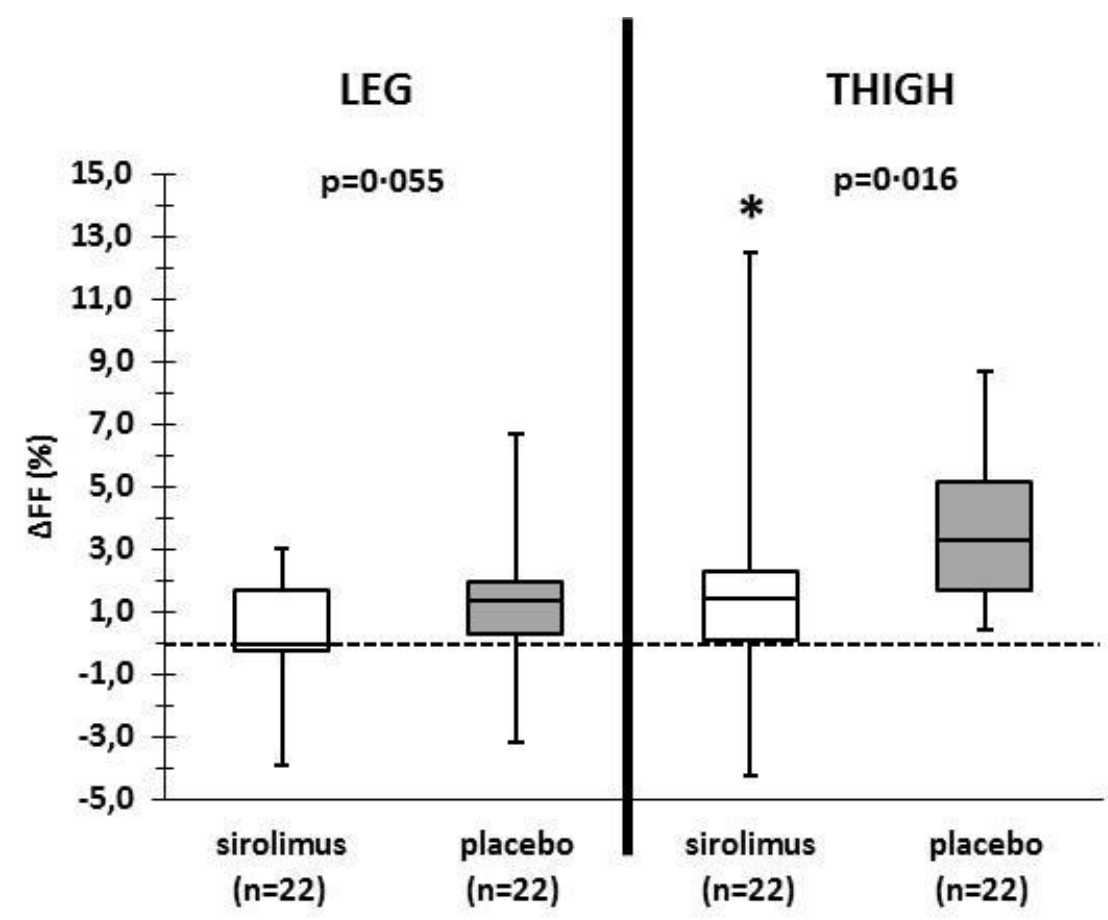

Supplementary Figure 3: Fat fraction (FF) evaluated by qNMRI in the leg and thigh.

Disease progression was evaluated using the 1-year changes in FF ( $\triangle \mathrm{FF}=\mathrm{FFM} 12-\mathrm{FFD} 0$, in \%) and was analyzed separately for the leg and thigh at 5 different levels in 22 patients in the sirolimus arm and 22 patients in the placebo arm. ${ }^{*} \mathrm{p}<0.05$. The median difference between group and $95 \% \mathrm{Cl}$ in $\mathrm{FF}$ was in leg $-1 \cdot 14[-1 \cdot 98 ; 0 \cdot 24]$ and in thigh $-1.84[-3 \cdot 75 ;-0.40]$. 

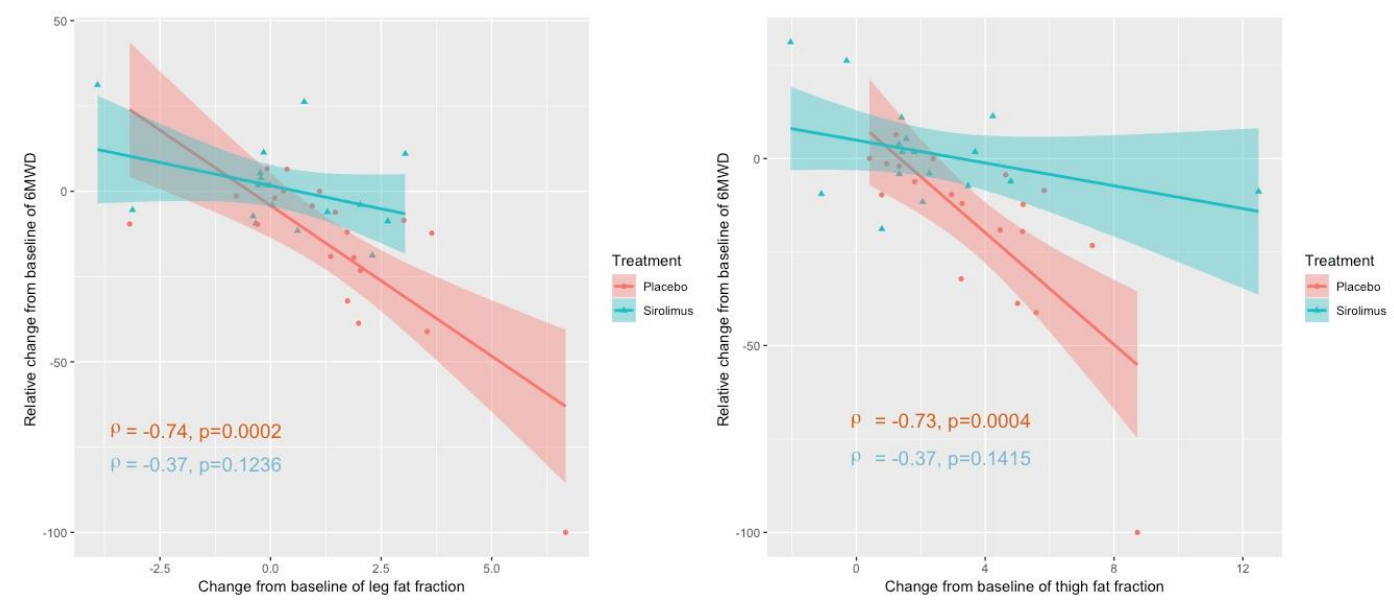

Supplementary Figure 4: Correlations between relative change from baseline of 6MWD and change from baseline of fat fraction (FF) evaluated by qNMRI in the leg and thigh. 
A

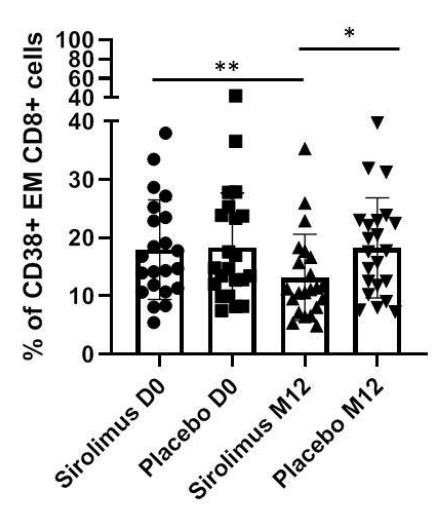

B

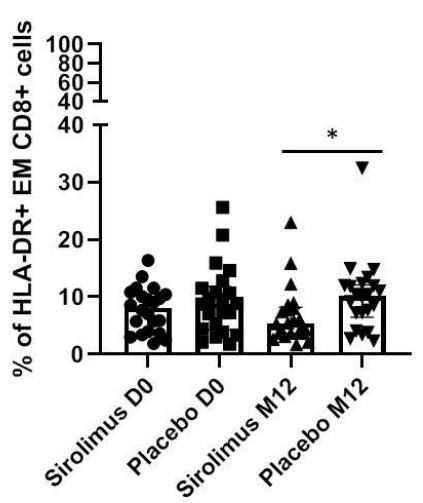

C

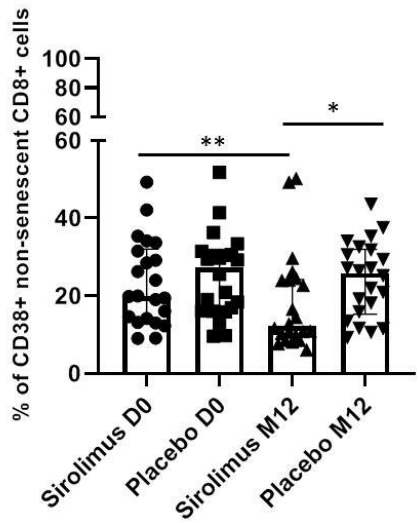

\section{Supplementary Figure 5: Expression of activation markers decreased in subsets of memory}

\section{CD8 cells.}

PBMCs from both groups were labelled individually with antibodies targeting surface antigens. Labelled cells were barcoded, pooled and stained with antibodies against intranuclear antigens. Unsupervised cell clustering was performed using the SPADE algorithm available on the cytobank cloud-based platform. Here, we show characteristics of memory CD8 T cell populations: A) the frequency of effector memory cells (EMs) expressing CD38, B) the frequency of EMs expressing HLA-DR and C) the frequency of nonsenescent CD8 cells (CD8+ T-bet+ CD57-) expressing CD38. The results were obtained using the Shapiro Wilk normality test, a paired t-test was implemented for intragroup comparisons, and an unpaired t-test was used for intergroup comparisons $\left({ }^{*} p<0.05,{ }^{* *} p<0.001\right)$. The data shown represent the median with interquartile. These analyses were performed in 22 patients in the sirolimus arm and 22 patients in the placebo arm. 

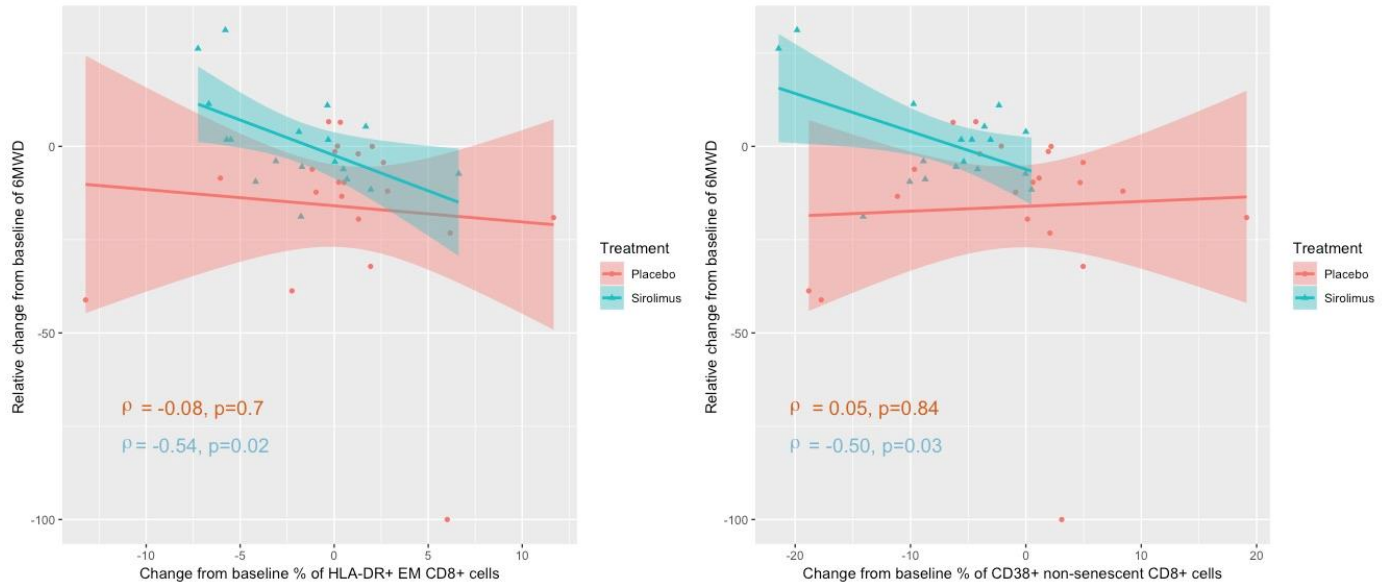

Supplementary Figure 6: Correlations between relative change from baseline of 6MWD and change from baseline of subsets of memory CD8 cells. 
Supplementary Tables

\begin{tabular}{|c|c|c|c|c|c|c|c|c|c|}
\hline Patients & Drugs & DO & D10 & M1 & M2 & M3 & M6 & M9 & M12 \\
\hline 1 & $S$ & $2 \cdot 0$ & $1 \cdot 5$ & $1 \cdot 5$ & $1 \cdot 5$ & $1 \cdot 5$ & $1 \cdot 5$ & $1 \cdot 5$ & 1.5 \\
\hline 2 & $P$ & $2 \cdot 0$ & $2 \cdot 0$ & $2 \cdot 0$ & $2 \cdot 0$ & $2 \cdot 0$ & $2 \cdot 0$ & $2 \cdot 0$ & $2 \cdot 0$ \\
\hline 3 & $P$ & $2 \cdot 0$ & $2 \cdot 0$ & $1 \cdot 5$ & $1 \cdot 5$ & $1 \cdot 2$ & $1 \cdot 2$ & $1 \cdot 2$ & $1 \cdot 2$ \\
\hline 4 & $P$ & $2 \cdot 0$ & $2 \cdot 0$ & $2 \cdot 0$ & $2 \cdot 0$ & $2 \cdot 0$ & $2 \cdot 0$ & $2 \cdot 0$ & $2 \cdot 0$ \\
\hline 6 & $S$ & $2 \cdot 0$ & $2 \cdot 0$ & $1 \cdot 5$ & $1 \cdot 0$ & $1 \cdot 5$ & $1 \cdot 5$ & $1 \cdot 5$ & 1.5 \\
\hline 7 & $S$ & $2 \cdot 0$ & $2 \cdot 0$ & $2 \cdot 0$ & $2 \cdot 0$ & $2 \cdot 0$ & $2 \cdot 0$ & $2 \cdot 0$ & $1 \cdot 2$ \\
\hline 8 & $S$ & $2 \cdot 0$ & $1 \cdot 5$ & $1 \cdot 7$ & $3 \cdot 0$ & $3 \cdot 0$ & $3 \cdot 0$ & $3 \cdot 0$ & $2 \cdot 0$ \\
\hline 9 & $\mathrm{P}$ & $2 \cdot 0$ & $1 \cdot 5$ & $1 \cdot 7$ & $1 \cdot 7$ & $1 \cdot 7$ & $1 \cdot 7$ & $1 \cdot 7$ & $1 \cdot 7$ \\
\hline 10 & $P$ & $2 \cdot 0$ & $2 \cdot 0$ & $1 \cdot 5$ & $1 \cdot 8$ & $1 \cdot 8$ & $1 \cdot 8$ & $1 \cdot 8$ & 1.5 \\
\hline 11 & $S$ & $2 \cdot 0$ & $2 \cdot 0$ & $2 \cdot 2$ & $2 \cdot 2$ & $2 \cdot 5$ & $2 \cdot 5$ & $2 \cdot 2$ & N.D. \\
\hline 12 & $S$ & $2 \cdot 0$ & $1 \cdot 5$ & $2 \cdot 0$ & $2 \cdot 6$ & $2 \cdot 6$ & $2 \cdot 6$ & $2 \cdot 6$ & $2 \cdot 6$ \\
\hline 13 & $P$ & $2 \cdot 0$ & $2 \cdot 0$ & $1 \cdot 5$ & $1 \cdot 5$ & $1 \cdot 2$ & $1 \cdot 5$ & 1.7 & 1.7 \\
\hline 14 & $P$ & $2 \cdot 0$ & $2 \cdot 0$ & $2 \cdot 0$ & $2 \cdot 0$ & $2 \cdot 0$ & $2 \cdot 0$ & $2 \cdot 0$ & $2 \cdot 0$ \\
\hline 15 & $S$ & $2 \cdot 0$ & $2 \cdot 0$ & $2 \cdot 0$ & $2 \cdot 0$ & $2 \cdot 0$ & & & \\
\hline 16 & $\mathrm{P}$ & $2 \cdot 0$ & $2 \cdot 0$ & $2 \cdot 0$ & $1 \cdot 7$ & $1 \cdot 7$ & $2 \cdot 0$ & $2 \cdot 0$ & $2 \cdot 0$ \\
\hline 17 & $P$ & $2 \cdot 0$ & $2 \cdot 0$ & $2 \cdot 0$ & $2 \cdot 0$ & $1 \cdot 5$ & 1.5 & 1.5 & 1.5 \\
\hline 18 & $S$ & $2 \cdot 0$ & $2 \cdot 0$ & $1 \cdot 5$ & $2 \cdot 3$ & $2 \cdot 3$ & $2 \cdot 3$ & & \\
\hline 19 & $S$ & $2 \cdot 0$ & $2 \cdot 0$ & $3 \cdot 0$ & 3.0 & $3 \cdot 0$ & $3 \cdot 0$ & $3 \cdot 0$ & $3 \cdot 0$ \\
\hline 20 & $P$ & $2 \cdot 0$ & $2 \cdot 0$ & $2 \cdot 0$ & $2 \cdot 0$ & $2 \cdot 0$ & $2 \cdot 0$ & $2 \cdot 0$ & $1 \cdot 7$ \\
\hline 21 & $S$ & $2 \cdot 0$ & $2 \cdot 0$ & $2 \cdot 0$ & $2 \cdot 0$ & $2 \cdot 0$ & $2 \cdot 0$ & 1.7 & 1.7 \\
\hline 22 & $S$ & $2 \cdot 0$ & $2 \cdot 0$ & $3 \cdot 0$ & $4 \cdot 0$ & $4 \cdot 0$ & & $2 \cdot 0$ & \\
\hline 23 & $P$ & $2 \cdot 0$ & 1.5 & $1 \cdot 2$ & $1 \cdot 2$ & $1 \cdot 2$ & 1.5 & 1.5 & 1.5 \\
\hline 24 & $S$ & $2 \cdot 0$ & $2 \cdot 0$ & $2 \cdot 0$ & $2 \cdot 0$ & & & & \\
\hline 25 & $P$ & $2 \cdot 0$ & $2 \cdot 0$ & $2 \cdot 0$ & $2 \cdot 0$ & $2 \cdot 0$ & $2 \cdot 0$ & $2 \cdot 0$ & $2 \cdot 0$ \\
\hline 26 & $P$ & $2 \cdot 0$ & $2 \cdot 0$ & $2 \cdot 0$ & $1 \cdot 5$ & $1 \cdot 5$ & 1.5 & 1.5 & $1 \cdot 5$ \\
\hline 27 & $P$ & $2 \cdot 0$ & $2 \cdot 0$ & $2 \cdot 0$ & $2 \cdot 2$ & $2 \cdot 2$ & $2 \cdot 2$ & $2 \cdot 2$ & $2 \cdot 2$ \\
\hline 28 & $S$ & $2 \cdot 0$ & $2 \cdot 0$ & & 1.5 & 1.5 & $2 \cdot 0$ & 1.7 & 1.7 \\
\hline 29 & $P$ & $2 \cdot 0$ & $2 \cdot 0$ & $2 \cdot 0$ & $2 \cdot 0$ & $2 \cdot 0$ & $2 \cdot 2$ & $2 \cdot 2$ & $2 \cdot 2$ \\
\hline 30 & $S$ & $2 \cdot 0$ & $2 \cdot 0$ & $2 \cdot 0$ & $2 \cdot 0$ & $2 \cdot 5$ & $2 \cdot 5$ & $2 \cdot 5$ & 2.5 \\
\hline 31 & $S$ & $2 \cdot 0$ & $2 \cdot 0$ & $2 \cdot 2$ & $2 \cdot 2$ & $2 \cdot 2$ & $2 \cdot 2$ & $2 \cdot 2$ & $2 \cdot 2$ \\
\hline 32 & $P$ & $2 \cdot 0$ & $2 \cdot 0$ & 1.5 & 1.5 & 1.5 & $2 \cdot 0$ & $2 \cdot 0$ & $2 \cdot 0$ \\
\hline 33 & $P$ & $2 \cdot 0$ & $2 \cdot 0$ & 1.5 & 1.5 & 1.7 & 1.7 & 1.7 & 1.7 \\
\hline 34 & $P$ & $2 \cdot 0$ & $2 \cdot 0$ & 1.5 & $2 \cdot 2$ & $2 \cdot 3$ & $2 \cdot 3$ & $2 \cdot 3$ & $2 \cdot 3$ \\
\hline 35 & $P$ & $2 \cdot 0$ & $2 \cdot 0$ & $2 \cdot 0$ & $2 \cdot 2$ & $2 \cdot 2$ & $2 \cdot 2$ & $2 \cdot 2$ & $2 \cdot 2$ \\
\hline 36 & $S$ & $2 \cdot 0$ & $2 \cdot 2$ & $2 \cdot 2$ & $2 \cdot 7$ & $2 \cdot 7$ & $2 \cdot 7$ & $2 \cdot 7$ & $2 \cdot 7$ \\
\hline 37 & $S$ & $2 \cdot 0$ & $2 \cdot 0$ & $2 \cdot 5$ & $3 \cdot 5$ & $4 \cdot 0$ & $4 \cdot 0$ & $4 \cdot 0$ & $4 \cdot 0$ \\
\hline 38 & $S$ & $2 \cdot 0$ & $2 \cdot 0$ & $2 \cdot 5$ & $2 \cdot 5$ & $2 \cdot 5$ & $2 \cdot 7$ & $2 \cdot 7$ & $3 \cdot 0$ \\
\hline 39 & $S$ & $2 \cdot 0$ & $2 \cdot 0$ & $3 \cdot 0$ & 3.0 & 3.0 & $3 \cdot 0$ & $3 \cdot 0$ & $3 \cdot 0$ \\
\hline 40 & $P$ & $2 \cdot 0$ & $2 \cdot 0$ & $2 \cdot 2$ & $2 \cdot 2$ & $2 \cdot 2$ & $1 \cdot 8$ & $1 \cdot 8$ & $2 \cdot 0$ \\
\hline 41 & $P$ & $2 \cdot 0$ & 2.0 & $2 \cdot 0$ & $2 \cdot 0$ & 1.5 & $1 \cdot 5$ & 1.5 & 1.5 \\
\hline 42 & $S$ & $2 \cdot 0$ & $2 \cdot 0$ & $2 \cdot 0$ & 0.7 & 0.7 & 0.7 & 0.7 & 0.7 \\
\hline 43 & $S$ & $2 \cdot 0$ & $2 \cdot 0$ & $2 \cdot 0$ & $2 \cdot 0$ & $2 \cdot 0$ & & 1.6 & 1.6 \\
\hline 44 & $S$ & $2 \cdot 0$ & $2 \cdot 0$ & $1 \cdot 7$ & $1 \cdot 7$ & $1 \cdot 7$ & $1 \cdot 7$ & 1.7 & $1 \cdot 7$ \\
\hline 45 & $P$ & $2 \cdot 0$ & $2 \cdot 0$ & 1.7 & 1.7 & 1.7 & 1.7 & N.D. & 1.7 \\
\hline
\end{tabular}


$\mathrm{S}$ (sirolimus) or $\mathrm{P}$ (placebo) was given in an oral solution at $1 \mathrm{mg} / \mathrm{mL}$. The doses delivered are shown in $\mathrm{mL}$. N.D. not done

Supplementary table 1: sirolimus and placebo adjustments over time 


\begin{tabular}{|c|c|c|}
\hline Antigen & $\begin{array}{l}\text { Metal element } \\
\text { tag }\end{array}$ & Manufacturer \\
\hline CD45 & 89 Actinium & Fluidigm \\
\hline HLADR & $\begin{array}{l}141 \\
\text { Praseodymium }\end{array}$ & Fluidigm \\
\hline CD19 & 142 Neodymium & Fluidigm \\
\hline CD5 & 143 Neodymium & Fluidigm \\
\hline CD4 & 145 Neodymium & Fluidigm \\
\hline $\lg \mathrm{D}$ & 146 Neodymium & Fluidigm \\
\hline CD28 & 147 Samarium & Fluidigm \\
\hline CD16 & 148 Neodymium & Fluidigm \\
\hline CD127 & 149 Samarium & Fluidigm \\
\hline $\mathrm{pRb}$ & 150 Neodymium & Fluidigm \\
\hline CD14 & 151 Europium & Fluidigm \\
\hline pAkt & 152 Samarium & Fluidigm \\
\hline pStat1 & 153 Europium & Fluidigm \\
\hline CD3 & 154 Samarium & Fluidigm \\
\hline CD45RA & 155 Gadolinium & Fluidigm \\
\hline CD1d & 156 Gadolinium & Fluidigm \\
\hline CD27 & 158 Gadolinium & Fluidigm \\
\hline CCR7 & 159 Terbium & Fluidigm \\
\hline T-bet & 160 Gadolinium & Fluidigm \\
\hline CD8 & 161 Dysprosium & Fluidigm \\
\hline FoxP3 & 162 Dysprosium & Fluidigm \\
\hline CD56 & 163 Dysprosium & Fluidigm \\
\hline CyclinB1 & 164 Dysprosium & Fluidigm \\
\hline IFN-y & 165 Holmium & Fluidigm \\
\hline CD24 & 166 Erbium & Fluidigm \\
\hline CD95 & 167 Erbium & Fluidigm \\
\hline CD138 & 168 Erbium & Fluidigm \\
\hline CD25 & 169 Thulium & Fluidigm \\
\hline iNKT & 170 Erbium & Fluidigm \\
\hline CXCR5 & 171 Ytterbium & Fluidigm \\
\hline CD38 & 172 Ytterbium & Fluidigm \\
\hline RORyT & 173 Ytterbium & Fluidigm \\
\hline CRTh2 & 174 Ytterbium & Fluidigm \\
\hline pHistone 3 & 175 Lutetium & Fluidigm \\
\hline CD57 & 176 Ytterbium & Fluidigm \\
\hline CD11b & 209 Bismuth & Fluidigm \\
\hline IdU & 127 lodine & Fluidigm \\
\hline ADN1 & 191 Iridium & Fluidigm \\
\hline ADN2 & 193 Iridium & Fluidigm \\
\hline Viability stain & Cisplatin & Fluidigm \\
\hline $\begin{array}{l}\text { Supplementary } \\
\text { cytometry }\end{array}$ & 2: Antibodies & used for mass \\
\hline
\end{tabular}




\begin{tabular}{|c|c|c|}
\hline & $\begin{array}{l}\text { Sirolimus } \\
(n=22)\end{array}$ & $\begin{array}{c}\text { Placebo } \\
(n=22)\end{array}$ \\
\hline \multicolumn{3}{|l|}{$6 \mathrm{MWD}$} \\
\hline Distance travelled (m) & $387 \pm 135$ & $344 \pm 134$ \\
\hline \multicolumn{3}{|l|}{ Myometry } \\
\hline Grip strength (daN) & $15 \cdot 4 \pm 7 \cdot 7$ & $13 \cdot 4 \pm 9 \cdot 9$ \\
\hline Elbow flexion strength (Nm) & $24 \cdot 4 \pm 8$ & $21 \cdot 9 \pm 13 \cdot 2$ \\
\hline Elbow extension strength $(\mathrm{Nm})$ & $19 \cdot 7 \pm 9 \cdot 5$ & $17 \cdot 7 \pm 15$ \\
\hline Knee flexion strength (Nm) & $33 \cdot 3 \pm 13 \cdot 8$ & $31 \cdot 6 \pm 15 \cdot 3$ \\
\hline Knee extension strength (Nm) & $28 \cdot 8 \pm 20 \cdot 4$ & $36 \cdot 9 \pm 33 \cdot 5$ \\
\hline
\end{tabular}

\begin{tabular}{|c|c|c|c|c|}
\hline & $\begin{array}{c}\text { Sirolimus } \\
(n=22)\end{array}$ & $\begin{array}{c}\text { Placebo } \\
(n=22)\end{array}$ & $\begin{array}{c}\text { Difference } \\
{[95 \% \mathrm{Cl}]}\end{array}$ & $\begin{array}{c}p \\
\text { value }\end{array}$ \\
\hline \multicolumn{5}{|l|}{ Primary endpoint } \\
\hline $\begin{array}{l}\text { Knee extension strength } \\
\text { (\% change at M6) }\end{array}$ & $\begin{array}{c}-7 \cdot 1(-12 \cdot 9- \\
4 \cdot 2)\end{array}$ & $\begin{array}{c}-8 \cdot 7(-15 \cdot 1- \\
-3 \cdot 8)\end{array}$ & $\begin{array}{c}1 \cdot 60[-5 \cdot 55 \\
12 \cdot 78]\end{array}$ & 0.44 \\
\hline \multicolumn{5}{|l|}{ Secondary endpoints } \\
\hline $\begin{array}{l}\text { Grip strength (\% change } \\
\text { at M6) }\end{array}$ & $-3 \cdot 7(-7 \cdot 7-0.5)$ & $\begin{array}{c}-5 \cdot 2(-18 \cdot 3- \\
0 \cdot 2)\end{array}$ & $\begin{array}{c}1 \cdot 54 \\
{[-2 \cdot 92 ; 13 \cdot 66]}\end{array}$ & 0.74 \\
\hline
\end{tabular}




\begin{tabular}{|c|c|c|c|c|}
\hline $\begin{array}{l}\text { Elbow flexion strength } \\
\text { (\% change at M6) }\end{array}$ & $\begin{array}{c}-1 \cdot 2(-10 \cdot 6- \\
6 \cdot 4)\end{array}$ & $\begin{array}{c}-8 \cdot 4(-12 \cdot 1- \\
2 \cdot 36)\end{array}$ & $\begin{array}{c}7 \cdot 19 \\
{[-4 \cdot 76 ; 13 \cdot 14]}\end{array}$ & 0.36 \\
\hline $\begin{array}{l}\text { Elbow } \quad \text { extension } \\
\text { strength (\% change at } \\
\text { M6) }\end{array}$ & $\begin{array}{c}-2 \cdot 15(-11 \cdot 1- \\
7 \cdot 3)\end{array}$ & $\begin{array}{c}-1 \cdot 8(-11 \cdot 1- \\
10 \cdot 6)\end{array}$ & $\begin{array}{c}3 \cdot 9 \\
{[-12 \cdot 3 ; 13 \cdot 3]}\end{array}$ & 0.63 \\
\hline $\begin{array}{l}\text { Knee flexion strength (\% } \\
\text { change at M6) }\end{array}$ & $\begin{array}{c}0.62(-11 \cdot 1- \\
15.9)\end{array}$ & $\begin{array}{c}-8 \cdot 11(-20 \cdot 2 \\
-3 \cdot 56)\end{array}$ & $\begin{array}{c}7 \cdot 49 \\
{[-3 \cdot 5 ; 23 \cdot 5]}\end{array}$ & 0.23 \\
\hline $\begin{array}{l}6 \text { MWD (\% change at } \\
\text { M6) }\end{array}$ & $\begin{array}{c}0.18(-3 \cdot 77- \\
6 \cdot 24)\end{array}$ & $\begin{array}{c}-6 \cdot 78(-9 \cdot 86- \\
1 \cdot 25)\end{array}$ & $\begin{array}{c}6 \cdot 96 \\
{[-0 \cdot 83 ; 11 \cdot 32]}\end{array}$ & 0.071 \\
\hline $\begin{array}{l}\text { IBMWCI (\% change at } \\
\text { M6 from D0) }\end{array}$ & $0(-14 \cdot 0-0)$ & $\begin{array}{c}0.083(-0.25 \\
-0)\end{array}$ & $\begin{array}{c}0.083 \\
{[-0.07 ; 0.21]}\end{array}$ & 0.46 \\
\hline $\begin{array}{l}\text { IBM-FRS (\% change at } \\
\text { M6 from D0) }\end{array}$ & $\begin{array}{c}0.029(0.07- \\
0.09)\end{array}$ & $\begin{array}{c}-0.035(-0.17 \\
-0.06)\end{array}$ & $\begin{array}{c}0.065 \\
{[-0.03 ; 0 \cdot 16]}\end{array}$ & 0.16 \\
\hline $\begin{array}{l}\text { HAQ-DI (Differences } \\
\text { from D0 to M6) }\end{array}$ & $\begin{array}{c}-0.09(-0.15- \\
0.05)\end{array}$ & $0.1(0-0.23)$ & $\begin{array}{c}-0 \cdot 19[-0 \cdot 29 ;- \\
0.03]\end{array}$ & 0.043 \\
\hline $\begin{array}{l}\text { * Quantitative data are expressed } \\
\text { Analyses are based on data obtaine } \\
\text { Hypothesis tests used to compare } \\
\text { approach: the worse-case scenario } \\
\text { FVC: Forced vital capacity } \\
\text { IBMWCI: IBM weakness composite } \\
\text { IBMFRS: IBM Functional Rating Sca } \\
\text { HAQ-DI: Health Assessment Questi } \\
\text { CK: Creatine kinase } \\
\text { FF: Fat fraction }\end{array}$ & $\begin{array}{l}\text { medians (Q1-Q } \\
\text { in the intention-tc } \\
\text { sirolimus with pl } \\
\text { s described in the } \\
\text { dex } \\
\text { nnaire without Dis }\end{array}$ & $\begin{array}{l}\text { Qualitative d } \\
\text { treat population } \\
\text { cebo were pe } \\
\text { Statistical Analy } \\
\text { bility Index }\end{array}$ & $\begin{array}{l}\text { re expresse } \\
\text { all endpoints } \\
\text { ed with a c } \\
\text { ection. }\end{array}$ & \\
\hline
\end{tabular}

